Portland State University

PDXScholar

1979

\title{
Washington County aftercare service utilization study
}

James Richard Peterson

Portland State University

Follow this and additional works at: https://pdxscholar.library.pdx.edu/open_access_etds

Part of the Counseling Commons, Psychiatric and Mental Health Commons, and the Social Work Commons

Let us know how access to this document benefits you.

\section{Recommended Citation}

Peterson, James Richard, "Washington County aftercare service utilization study" (1979). Dissertations and Theses. Paper 2771.

https://doi.org/10.15760/etd.2767

This Thesis is brought to you for free and open access. It has been accepted for inclusion in Dissertations and Theses by an authorized administrator of PDXScholar. Please contact us if we can make this document more accessible: pdxscholar@pdx.edu. 
WASHINGTON COUNTY AFTERCARE

SERVICE UTILIZATION STUDY

by

JAMES RICHARD PETERSON

A practicum submitted in partial fulfillment of the requirements for the degree of.

MASTER OF SOCIAI WORK

Portland State University

1979 
TO THE OFFICE OF GRADUATE STUDIES AND RESEARCH:

The Advisor approves the research practicum of James Richard Peterson presented June 5, 1979. 
TABLE OF CONTENTS

PAGE

LIST OF TABLES . . . . . . . . . . . . . . viii

LIST OF FIGURES . . . . . . . . . . . . . . xiii

CHAPTER

I INTRODUCTION . . . . . . . . . . . . I

A Developing Aftercare Service

Delivery System . . . . . . . . . 1

The Washington County Aftercare

Service Providers ........... 2

Washington County Mental

Health Program

Tualatin Valley Mental

Health Center

Tualatin Valley Workshop

Metropolitan Family service

Lutheran Family Services

Native American Rehabilitation

Centro Cultural

Cedar Hills Psychiatric Hospital (Inpatient)

The Decision to Evaluate . . . . . . 5

II METHODOLOGY . . . . . . . . . . . . 6

Operationalizing The Research Purpose . . 6

The Research Questions . . . . . . 7 
TABLE OF CONTENTS

(Continued)

CHAPTER

PAGE

II

The Research Questions, cont'd . . . . 7

Part One - Population Demographic,

Clinical, and Service Utilization

Characteristics.

Part Two - Differentiating the Chronic Aftercare Population.

Part Three - The Relationship Between the Utilization of Mental Health Subcontract Agencies and Selected Variables.

Part Four - The Relationship Between the Utilization of Services Coordination and Selected Variables.

Part Five - The Chronological Relationship Between the Utilization of Aftercare Services and Admission to the State Hospital.

The Research Population . . . . . . 10 The Study Time Frame . . . . . . . . . 11 Data Collection . . . . . . . . 12 In Search of a Comparative Study . . . 15 Data Analysis . . . . . . . . . 17

III THE RESEARCH FINDINGS . . . . . . . . . 19

Part One - Population Demographic, Clinical and Service Utilization Characteristics. 20

Section 1: Demographic Profile Characteristics.

Section 2: Clinical Characteristics. 
TABLE OF CONTENTS

(Continued)

CHAPTER

PAGE

III

Part One - , cont'd. . . . . . . 20

Section 3: Service Utilization

Characteristics.

Part Two - Differentiating the Chronic

Aftercare Population . . . . . . . . 43

Section 1: The Relationship Between Selected Subject Characteristics and the Number of Dammasch State Hospital Admissions Incurred Between June 31, 1976 and July 1, 1978 .

Section 2: The Relationship Between Selected Subject Characteristics and Total Days in the Hospital.

Section 3: The Relationship Between Selected Subject Characteristics and Primary Diagnosis.

Section 4: The Relationship Between Selected Subject Characteristics and Hospital Commitment Type.

Part Three - The Relationship Between the Utilization of Mental Health Subcontract Agencies and Selected Variables. . . . 80

Section 1: Agency Utilization and Duration of Treatment.

Section 2: Agency Utilization and Gross Family Income.

Section 3: Agency Utilization and Location of Residence.

Section 4: Agency Utilization and Hospital Admissions. 


\section{TABLE OF CONTENTS}

(Continued)

Part Three - , cont'd......... 80

Section 5: Agency Utilization and Total Days in the Fospital.

Section 6: Agency Utilization and Primary Diagnosis.

Section 7: Agency Utilization and Hospital Commitment Type.

Section 8: Agency Utilization and Acknowledgement of Treatment Termination.

Part Four - The Relationship Between the Utilization of Services Coordination and Selected Variables......... 100

Section 1: Services Coordination and the Utilization of Subcontract Agencies.

Section 2: Services Coordination and Total Days in Community Treatment.

Section 3: Services Coordination and Acknowledgement of Treatment Termination.

Part Five - The Chronological Relationship Between the Utilization of Aftercare Services and Admission to the State Hospital ............. 106

Section 1: Proportion of Subjects in Treatment (Subcontract Services) Just Prior to Hospitalization. 


\section{TABLE OF CONTENTS}

(Continued)

III

$$
\text { Part Five - , cont'd ......... . . . . . . } 06
$$

Section 2: Service Utilization Patterns Following Hospital Discharge and Hospital Recidivism.

IV SUMMARY OF THE RESEARCH FINDINGS . . . . . .123 


\section{LIST OF TABLES}

TABLE

PAGE

Al Age Distribution . . . . . . . . . . . . . . 21

AlA Age Comparisons of Two Aftercare Study

Populations . . . . . . . . . . . . . . 22

A2 Sex Distribution . . . . . . . . . . . . 23

A3 Marital Status Distribution . . . . . . . . . 24

A4 Race Distribution . . . . . . . . . . . . 24

A5 Primary Income Source Distribution . . . . . . 26

A5A Distribution of Subjects with Only One Reported Primary Income Source . . . . . . . . . . 27

A6 Distribution of Gross Family Income . . . . . . . 28

A7 Distribution of Last known Residence . . . . . 30

A7A Population Distribution Comparison . . . . . . 30

B1 Primary Diagnosis Distribution . . . . . . . . 31

B2 Distribution of Admissions to Dammasch State Hospital (July 1, 1976 to June 31, 1978) . . . 32

B2A Distribution of Admissions to Dammasch State Hospital -- Life Time . . . . . . . . . 33

B3 Distribution of Total Days in Hospital (July 1, 1976 to August 31, 1978) . . . . . . 34 B4 Distribution of Commitment Types . . . . . . . 35 


\section{LIST OF TABLES}

(Continued)

TABLE

PAGE

B4A Subjects with at Least one Court Commitment During Study Period . . . . . . . . . 35

Cl Utilization of Services Coordination . . . . 36

C2 Utilization of Subcontract Agencies . . . . . 37

C3 Number of Agencies Utilized . . . . . . . 38

C4 Duration of Community Treatment . . . . . . 39

C5 Clients Reported on MEDS (Tualatin Valley

Mental Health Center)........... 40

C6 Types of Treatment Termination ........ . 42

DlA Age and Number of Hospital Admissions . . . . 44

DlB Sex and Number of Hospital Admissions . . . . 45

DIC Marital Status and Number of Hospital Admissions. 46

DID Race and Number of Hospital Admissions . . . . 46

D1E Primary Income Source and Number of Hospital Admissions . . . . . . . . . . . 47

DIF Gross Family Income and Number of Hospital Admissions . . . . . . . . . . . 48

DIG Residence and Number of Hospital Admissions . . 49

DIH Primary Diagnosis and Number of Hospital Admissions . . . . . . . . . . . 50

D2A Age and Number of Hospital Days . . . . . . 52 


\section{LIST OF TABLES}

(Continued)

TABLE

PAGE

D2B Sex and Number of Hospital Days . . . . . 52

D2C Race and Number of Hospital Days . . . . . . 53

D2D Marital Status and Number of Hospital Days . . 55

D2E Primary Income Source and Number of Hospital

Days ................ . 57

D2F Gross Family Income and Number of Hospital Days . 59

D2G Residence and Number of Hospital Days . . . . 61

D2H Primary Diagnosis and Number of Hospital Days • • 63

D3A Age and Primary Diagnosis . . . . . . . . 64

D3B Sex and Primary Diagnosis .......... 65

D3C Marital Status and Primary Diagnosis . . . . 66

D3D Race and Primary Diagnosis . . . . . . . . 67

D3E Primary Income Source and Primary Diagnosis . . 68

D3F Gross Family Income and Primary Diagnosis . . . 69

D3G Residence and Primary Diagnosis . . . . . • 71

D4A Age and Commitment Type . . . . . . . . 72

D4B Sex and Commitment Type . . . . . . . . 73

D4C Marital Status and Commitment Type . . . . . 73

D4D Race and Commitment Type . . . . . . . . 74

D4E Primary Income Source . . . . . . . . . 75

D4F Gross Family Income and Commitment Status • • • 76 


\section{LIST OF TABLES}

(Continued)

TABLE

PAGE

D4G Residence and Commitment Status . . . . . . 78

D4H Primary Diagnosis and Commitment Type . . . . 79

El Duration of Community Treatment by Agency . . . 81

E2 Agency Utilization and Gross Family Income . . 83

E3 Agency Utilization and Hospital Admissions . . 91

E4 Agency Utilization and Total Days in the Hospital. 93

E5 Agency Utilization and Primary Diagnosis . . . 95

E6 Agency Utilization and Hospital Commitment Type . 97

E7 Agency Utilization and Acknowledgement of

Treatment Termination . . . . . . . . . 99

Fl Services Coordination and the Utilization of Subcontract Agencies ........... 101

F2 Services Coordination and Total Days in

Community Treatment . . . . . . . . 103

F3 Services Coordination and Acknowledgement of

Treatment Termination . . . . . . . . 105

G1 Subjects in Treatment at or Just Prior to

Hospital Admission . . . . . . . . . 107

G2 Utilization of Aftercare Services During

Community Stay Periods . . . . . .... 109

G3 Utilization of Aftercare Services and Readmission Rates . . . . . . . . ...... 111 


\section{LIST OF TABLES}

(Continued)

TABLE

PAGE

G3A. Utilization of Subcontract Agencies and Readmission Rates . . . . . . . . . . 113

G4 Utilization of Services Coordination and Readmission Rates . . . . . . . . . 114

G5 Readmission Rates for Service Coordination Clients by Commitment Status . . . . . . 116

G6 Return Rates by Service Type Category . . . . 118:

G7 Diagnostic Characteristics by Service Type Category . . . . . . . . . . . . 119

G8 Commitment Status Characteristics by Service Type Category . . . . . . . . . . . 120 


\section{LIST OF MAPS}

MAP

PAGE

1. Geographic Distribution of Washington County's Chronic Aftercare Population . . . . . . . . 85

2. Service Location and Client Distribution for Lutheran Family Service .. . . . . . . . . . 86

3. Service Location and Client Distribution for Metropolitan Family Service . . . . . . . . 87

4. Service Location and Client Distribution for Tualatin Valley Mental Health Center . . . . . 88

5. Service Location and Client Distribution for Tualatin Valley Workshop . . . . . . . . . . 89 
CHAPTER I

INTRODUCTION

\section{A Developing Aftercare Service Delivery System}

Prior to 1977, the only private agency in Washington County providing mental health services to former Dammasch clients was Tualatin Valley Mental Health Center. Except for medication monitoring and counseling services available through this agency, the only other organized aftercare service was delivered by the Mental and Emotional Disturbances Division of the Washington County Mental Health Program. For the most part, this aftercare service was limited to civil commitment case monitoring activities. Recognizing that a greater variety of community mental health services was needed, the Mental Health Program initiated efforts beginning in 1976 to locate private sector agencies willing to develop and provide aftercare services on a subcontract basis. At the same time, the aftercare direct service delivery capabilities of the Mental Health. Program was expanded. Service coordination was enlarged to make it available not only to civil commitment clients but all aftercare clients. Special services were established to make aftercare clients more aware of the variety of community mental health services available to them and to 
facilitate the provision, coordination and continuity of these services on an individual need basis. By spring of 1977, the number of aftercare direct service providers had grown from a single county program (division) and subcontract agency to two county programs and seven subcontract agencies. The next section provides a description of these programs/agencies.

\section{The Washington County Aftercare Service Providers}

The agency and program descriptions provided in this section are characteristic of what existed prior to July, 1978. Additionally, only those agencies and programs who. had direct services available to the aftercare population are presented. For a more complete and up-to-date description of the Washington County Mental Health system, the reader is referred to the 1979-1981 Biennium County Mental Health Plar..1

Washington County Mental Health Program

The Mental Health Program and its four service divisions (Alcohol, Developmental Disabilities, Drug, and Mental and Emotional Disturbances) are responsible for the planning and administration of the County's Community

${ }^{1}$ Washington County Mental Health Program. Washington County Mental Health Plan For The 1979-1981 Biennium. Hillsboro, Oregon: 1979 
Mental Health System which is primarily comprised of private sector subcontract agencies. While most direct services are provided through the subcontractors, some services which are required by legislation but not available in the private sector, are delivered by program staff. During most of the two-year period between July 1, 1976 and June 31, 1978, in-house (program) direct services were available to the post psychiatric hospital population through the Mental and Emotional Disturbances Division and the Drug Division. In the Mental and Emotional Disturbances Division, staff conducted screening, disposition planning, and case monitoring for individuals involved in a civil commitment. Aaditionally, services coordination activities for persons pre and post psychiatric hospitalization were available.

In the Drug Division, outpatient drug treatment services were available to aftercare clients with drug-related disorders.

\section{Tualatin Valley Mental Health Center}

The center is the largest mental and emotional and alcohol disturbance contractor. The primary aftercare services provided by the Genter's staff are medication monitoring as well as other forms of individual and group treatment. 
Tualatin Valley Workshop

The aftercare services provided through the workshop encompass primarily two programs:

1. The Day Treatment program provides medication monitoring, individual and group counseling as well as individual living skills development.

2. The sheltered vorkshop program provides pre-vocational evaluation, work adjustment training, sheltered employment, and placement in competitive employment.

Metropolitan Family Service

This service provides primarily family focused counseling services to individuals, couples, and families. Additionally, homemaker services are available to the more severely disturbed or homebound clients.

\section{Lutheran Family Services}

This agency provides individual, family, and group counseling services. In addition, life education classes in parenting, relaxation and stress management, and assertiveness training are offered. While services are not specifically targeted for aftercare individuals, they are available to this population.

\section{Native American Rehabilitation Association}

This association is located in Portland and provides outpatient and short term inpatient alcohol treatment 
services to American Indian clients who live in Washington County.

Centro Cultural

This program offers outpatient alcohol counseling services to members of the Spanish-speaking community.

\section{Cedar Hills Psychiatric Hospital (Inpatient)}

Short term inpatient psychiatric hospitalization is the only contract service offered through this facility.

\section{The Decision to Evaluate}

By the summer of 1978, most of the agencies and programs covered above had been an operating part of the Aftercare Delivery System for over a year. While it was evident that the number of services available to Dammasch releasees had dramatically increased since 1976, the actual impact the system was having on the aftercare population, and particularly the more chronically ill members of this group, was unknown. In order to obtain some understanding of this system's impact the following study was undertaken. 


\title{
CHAPTER II
}

\author{
METHODOLOGY
}

\section{Operationalizing The Research Purpose}

Broadly speaking, the purpose of this study is to:

1. Assess the functioning of the psychiatric hospital aftercare service delivery system by examining community service utilization patterns. of Dammasch Hospital releasees.

2. Obtain descriptive information relating to Washington County's chronic aftercare population.

3. Provide an objective data base that can be used to further develop the Aftercare Service Delivery System in Washington County.

During the summer months of 1978, the researcher and two representatives of the County Mental Health Program engaged in a process, spanning many meetings, aimed at operationalizing the purpose of the research. This process began with an abstract statement of the information the Program wanted to get out of the study, and progressed through various levels of fine tuning in which information needs. were clarified and ultimately operationalized in the form of specific research questions. 


\section{The Research Questions}

The research questions are grouped into five parts.

Part One - Population Demographic, Clinical, and Service Utilization Characteristics.

1. What are the demographic characteristics of the research population:
a. age,
b. sex,
c. marital status,
d. race,
e. primary income source,
f. gross family income,
g. location of residence?

2. What are the clinical characteristics of the subjects:
a. primary diagnosis,
b. number of readmissions during time frame,
c. total days in the state hospital during time frame,
d. hospital commitment type?

3. How many subjects used services coordination during the time frame?

4. How many subjects utilize community treatment services through the various subcontract agencies and County programs?

5. How many treatment programs/agencies tend to be utilized by individual subjects? 
6. What is the duration of community treatment?

7. How many subjects utilize medication monitoring services?

8. What are the conditions of treatment tefmination?

Part Two - Differentiating the Chronic Aftercare Population.

1. Is there a difference in demographic/diagnostic characteristics (all variables) of those subjects with:
a. 1 admission,
b. 2 admissions,
C. 3 or more admissions?

2. Is there a difference in the demographic/diagnostic characteristics of subjects whose total days in Dammasch State Hospital are:
a. 1 to 30 days,
b. 31 to 60 days,
c. 61 to 90 days,
d. 91 to 120 days,
e. 121 to 150 days,
f. 151 to 180 days,
g. 181 plus days?

3. Is there a difference in demographic characteristics of subjects whose primary diagnosis is:
a. psychotic disturbances,
b. alcohol/drug disturbances
c. other mental and emotional disturbances? 
4. Is there a difference in demographic/diagnostic characteristics of subjects whose hospital entry is: a. court committed?

b. non-court committed?

Part Three - The Relationship Between the Utilization of Mental Health Subcontract Agencies and Selected Variables.

1. Does duration of treatment differ from one program/ agency to another?

2. Does gross family income relate to the utilization of community treatment programs/agencies?

3. Does location of residence relate to the utilization of community treatment programs/agencies?

4. Does the number of Dammasch Hospital Admissions incurred by a subject relate to the utilization of community treatment programs/agencies?

5. Does the total Dammasch Hospital days relate to the utilization of community treatment programs/agencies?

6. Does primary diagnosis relate to the utilization of community treatment programs/agencies?

7. Does hospital commitment type relate to the utilization of community treatment programs/agencies?

8. Do the conditions of treatment termination differ from one community treatment agency to another? 
Part Four - The Relationship Between the Utilization of Services Coordination and Selected Variables.

1. Does the utilization of services coordination relate to the utilization of community treatment services?

2. Does the utilization of services coordination relate to the duration of community treatment?

3. Does the utilization of services coordination relate to the condition of treatment termination?

Part Five - The Chronological Relationship Between the Utilization of Aftercare Services and Admission to the State Hospital.

1. What percent of the population were in treatment at the time of admission/readmission to Dammasch?

2. What is the relationship between the utilization of aftercare services and readmission to Dammasch?

\section{The Research Population}

The selection of the study population was guided by three factors:

1. Due to resource limitations, the maximum size of the study population would have to be no larger than 100 to 120 subjects.

2. Washington County residents who tended to incur multiple Dammasch hospitalizations were identified early in the operationalizing process as the primary target of aftercare service delivery efforts. Therefore, information pertaining to the more chronically hospitalized 
portion of the aftercare population was established as a high priority.

3. The aftercare delivery system as described earlier was not operational until late 1976 and early 1977. Thus, data collection would have to be limited to subjects who left Dammasch just prior to or after this time period. Using the above guidelines, the Oregon State Mental Health Information System was contacted for assistance in identifying a population suitable for this study. The result of this contact was the development of a list which contained the names of all the former and current Dammasch Hospital patients who had incurred at least 2 hospital admissions from Washington County prior to July 1,1978 and had no less than 1 of the admissions occur after June 31 , 1976. This list of 118 names became the Study Population List. However, one name was dropped from this list. The reason for the deletion will be covered in the next section.

\section{The Study Time Frame}

July 1, 1976 through June 31, 1978 was the time frame (study period) for this research effort. Only data generated during this time period was utilized for data analysis. The beginning of this two year span slightly precedes the expansion of the Mental Health Program's client services coordination activities and ends just prior to the initial planning stage of the research. 


\section{Data Collection}

The two primary data sources used in this research effort were the Oregon State Mental Health Information System and the client case files maintained by the individual aftercare programs and subcontract agencies which served the study population.

While working on the development of the population subject list, it was learned that the State's Mental Health Information system routinely collected and maintained almost all of the data needed for the study. After determining that the required data could be accessed and used for this study, computer printouts containing demographic, clinical, and washington County aftercare service utilization information on all but one of the subjects was obtained. Information relating to the one subject was not reported due to a coding error. Rather than access the system again for information on one individual, it was decided that the name would be dropped from the subject list.

A review of the computer printouts supplied by the State Mental Health Information system revealed that substantial portions of the data were not consistantly reported on each subject. The items most often found to be missing were primary income source, gross family income, residence, and aftercare service utilization information. 
In order to obtain the missing data items, it was decided that individual subject case files maintained by the aftercare programs and agencies would be utilized.

The Administrator of each agency identified as an Aftercare Service provider for this study received a letter from the Director of the Washington County Mental Health Program outlining the nature and purpose of the study. The letter was also followed up with individual and group meetings between the researcher and the various administrators to further clarify the purpose of the study and specify the data that would be needed. Additionally, a series of negotiating sessions were conducted involving Mental Health Program management staff and the respective agency administrators. These negotiations resulted in agreement of the following data collection procedures: 1. Each agency and program administrator would be individually contacted to set up a convenient time for the researcher to visit the agency for data collection purposes.

2. Basically, three options were available to the administrators regarding the researcher's access to client case files.

a. The researcher would be denied direct access to the client case files. Utilizing a sample Population name list, agency staff would pull the case files of subjects who had been clients during the study 
period. Then, in the presence of the researcher, a staff member would search the file for the needed information and provide it verbally to the researcher for recording.

b. The researcher would be denied access to file storage areas, but would be allowed direct access to subject case files; as in the previous option, a subject name list would be used to locate files of persons who had been program/agency clients during the study period. However, once the appropriate files were located, they would be available to the researcher.

c. The researcher would have full access to file storage areas and the subject case files on hand. Basically, the researcher was given full responsibility for locating appropriate files and extracting the needed data from them.

Option "a" was utilized by one agency and option "c" by four service providers. ${ }^{2}$ The Mental Health Drug Program, Centro Cultural, and NARA were supplied subject lists and reported no client contacts with any of the subjects during the study period.

2 Data pertaining to Cedar Hills (in-patient) service utilization is kept by the MED program. Thus, Cedar Hills client files were not directly accessed. 
As data collection proceeded, the transient nature of the study population became quickly evident. Since there seemed to be considerable subject movement between Washington and Multnomah Counties, it was decided by both the researcher and the Mental Health Program Director that some determination of the extent to which the study group used Multnomah County aftercare services would be needed. The Director of the Multnomah County Mental Health Division was contacted and access to the needed service utilization information was requested. Following consultation with the Director of the State Mental Health Division, the researcher was allowed access to the master client card files maintained at the East County Clinic. Besides name and birth date, the card files consistently reported clinic admission information on current and former clients of the four Multnomah County Mental Health outpatient clinics. Since clinic discharge dates were nọt routinely reported, only information pertaining to subject admissionsduring the study period was extracted from the master card file.

\section{In Search of a Comparitive Study}

Following data collection, a literature search for comparable aftercare service utilization studies was undertaken. It was hoped that such an effort would provide comparisons against which the population and services 
utilization findings of the current study could be assessed. The only study found to have a similar focus was a rather extensive research effort which examined the de-institutionalization process in the states of Washington and Idaho. ${ }^{3}$. In all, this study involved seven substudies. The one of most interest (for the current purpose) was a post hospital client follow-up study which contacted a sample of 496 aftercare subjects, 24 mental health centers, 6 satellite clinics, and 53 residential facilities to determine the extent of service utilization following hospital discharge.

The study sample for the Washington/Idaho State study was comprised of subjects who had been discharged from one of the four psychiatric state hospitals in Washington and Idaho during Fiscal year 1975-1976. Since the number of hospital admissions (other than one) was not a selection criterion, this sample tended to have fewer life-time hospitalizations than the Washington County study group. The diagnostic categories for both groups were similar except that the Washington/Idaho sample did not include subjects with alcohol or ôrug disorders (these individuals were excludedi.

${ }^{3}$ H. Max Drake, et al. An Evaluation of the Deinstitutionalization Process in the U.S. Department of Health, Education, and Welfare, Region $X$. Olympia, Washington: 1978 
In spite of the differences in some of the selection criterion used, it was felt that some of the population data from the Washington/Idaho state study would be useful as a comparison in the current study. However, the service utilization data from the Washington/Idaho study was not used. The primary consideration in making this decision was the differences in the size (geographic and number of service providers) and scope (types of services) of the two systems studied. Because of these differences, it was felt that attempts to make comparisons would be awkward and susceptible to misinterpretations.

\section{Data Analysis}

Following data collection, the information obtained on each subject was coded and placed on key punch cards for transfer to a computer disk file. The SPSS data analysis package was then used with assistance from the programming consultant at the Regional Research Institute. Most of the data analysis found in the next chapter was obtained through computer analysis. A few analyses which would have required special programming beyond the capabilities of SPSS were done by hand. 
CHAPTER III

THE RESEARCH FINDINGS

Through a review of clinical case files and data supplied by the Oregon State Mental Health Information System, data relating to the demographic, clinical, and community service utilization characteristics (profiles) of the chronic aftercare study population were obtained. In this chapter the content and relationship between sub-elements of the three data profiles will be described. The research findings are presented in five parts:

1. Part One will be concerned with identification of the demographic, clinical, and service utilization characteristics of the research population.

2. Part Two will examine the relationship between various chronic aftercare population characteristics and selected clinical profile variables.

3. Part Three will delve into the relationship between the utilization of Washington County Community Mental Health subcontract agencies and selected subject profile variables.

4. Part Four will attempt to clarify the relationship between the utilization of services coordination and other utilization profile variables. 
5. Part Five will specify the chronological relationship between utilization of aftercare services and admission to the state hospital.

As the study findings are reviewed, the following factors should be considered:

1. Since all of the subject characteristic information contained in this study were obtained from secondary sources, there was little control over maintaining data reliability. Based on personal experience with the reporting forms $(C L-1)$ used to initially record client characteristics, there is likely to be two types of errors inherent in this data which might be. kept in mind: a. Recorder error; information is incorrectly or inaccurately coded by the recorder. b. Reporter error; incorrect information is reported by the subject.

2. Primary income source, gross family income, and location of residence information was inconsistently reported. Typically, only one measure was obtained for most of the subjects on each of these variables. Since these one time measures can only be considered characteristic of the point in time they were originally recorded; they will not necessarily be generalizable over the entire study period.

3. Much of the data analysis is concerned with examining the relationship between variables. Because of design 
limitations, the analysis used in this study will focus on determining if certain relationships exist and not whether one variable causes changes in another variable (causal relationship).

Part One - Population Demographic, Clinical and Service Utilization Characteristics.

In the following sections, a descriptive picture of the demographic, clinical, and aftercare service utilization characteristics of the study population will be provided. As a comparative tool, selected demographic and/or clinical characteristics of the aftercare sample will be matched against the characteristics of the general population ${ }^{4}$ (Oregon State or Washington County) and in some cases a study sample of aftercare patients in the states of Washington and Idaho. This latter aftercare population was used in a deinstitutionalized study of psychiatric hospital releases in these two states (see MethodologyIn search of a Comparative study). It is felt that these comparisons will provide a referent against which the unique nature of the study population can be measured. Unfortunately, due to limits relating to the comparability. of individual data categories,comparisons will not be

${ }^{4}$ Population characteristics throughout the report were derived from data provided by The Center for Population Research and Census, Portland State University. 
available on most of the clinical and all of the utilization profile variables.

Section 1: Demographic Profile Characteristics

Age: The median age for this group is 36 which is higher than the estimated median age of 26 for Washington County's general population. While the study subjects tend to be older than the general population, they are slightly younger than a similar but less chronically ill study sample in Washington and Idaho (See Talbe AlA).

\section{POPULATION DEMOGRAPHIC PROFIIES}

\section{TABLES}

TABLE AI: AGE DISTRIBUTION

AGE
\begin{tabular}{|l|c|l|}
\hline 12 to 17 Years & 1 & $(8)$ \\
\hline 18 to 44 Years & 78 & $(.98)$ \\
\hline 45 to 64 Years & 29 & $(66.78)$ \\
\hline 65 P1us Years & 9 & $(24.88)$ \\
\hline TOTAL & 117 & $(7.78)$ \\
\hline RANGE OF AGES: & 16 to 80 Years & $(100.08)$ \\
MEAN AGE: & 39 Years & \\
MEDIAN AGE : & 36 Years & \\
\hline
\end{tabular}


TABLE AIA: AGE COAPARISOINS OF TWO AFTERCARE STUDY POPULATIONS

AGE RANGE
\begin{tabular}{|l|c|c|} 
COUNTY STUDY SAMPLE & ( $)$ WASH \\
\hline 18 to 34 yrs. & 498 & 458 \\
\hline 36 to 45 yrs. & 438 & 458 \\
\hline 65 plus yrs. & 88 & 108 \\
\hline
\end{tabular}


Sex: The study population is made up of 528 males and $48 \%$ females. These figures are almost inverse to the proportion of males (49\%) to females (51\%) in the general population of Washington County.

TABLE A2: SEX DISTRIBUTION

\begin{tabular}{|l|c|r|} 
SEX & $\mathrm{N}$ & $(8)$ \\
\hline Male & 61 & $(52.18)$ \\
\hline Female & 56 & $(47.98)$ \\
\hline TOTAL & 117 & $(100.08)$ \\
\hline
\end{tabular}

Marital Status: Just under one third (31.6\%) of the subjects have never been married. This is slightly higher than the 25.18 figure for single individuals state wide. Additionally, while 61.28 of Oregon's population is married (but not separated) only $30.8 \%$ of the research population falls into the same category. Another large disparity is noted when the proportion (26.58) of divorced subjects in the study group is compared to the proportion (6.28) of divorced individuals in the general population. Finally, while $11.1 \%$ of the subjects are either separated or widowed, only $7.6 \%$ of the population are so classified state wide. 
TABLE A3: MARITAL STATUS DISTRIBUTION

\begin{tabular}{|l|c|r|}
\hline MARITAL STATUS & $\mathrm{N}$ & $(8)$ \\
\hline Single & 37 & $(31.68)$ \\
\hline Married & 36 & $(30.88)$ \\
\hline Divorced & 31 & $(26.58)$ \\
\hline Separated & 7 & $(6.08)$ \\
\hline Widowed & 6 & $(5.18)$ \\
\hline TOTAI & 117 & $(100.08)$ \\
\hline
\end{tabular}

Race: The research population is predominantly white (93.18) with Mexican-American, American Indian and Oriental ethrics making up $6.9 \%$ of the population. Considering that the percent of non-whites in the county's general population is less than three percent, it would appear that ethnic minorities may be over represented in the study group.

TABLE A4: RACE DISTRIBUTION

\begin{tabular}{|l|c|r|}
\hline RACE & $\mathrm{N}$ & $(8)$ \\
\hline White & 109 & $(93.18)$ \\
\hline Mexican American & 3 & $(2.68)$ \\
\hline American Indian & 2 & $(1.78)$ \\
\hline Oriental & 3 & $(2.68)$ \\
\hline TOTAL & 117 & $(100.08)$ \\
\hline
\end{tabular}


Primary Source of Income: In reporting their primary source of income, subjects were asked to identify the one income source which provides them with their primary monetary support. Since only one income source was asked for, information relating to secondary sources of income were for the most part not available. However, primary income source information is usually collected each time a subject enters or re-enters treatment. Thus, it was possible to obtain more than one measure on this variable over the two year study period. In all, primary income source information was obtained on 108 of the 117 research subjects. Many (82) of these individuals had only one reported primary income source over the two year time period; 25 had two and 1 subject had three recorded primary income sources. Self/family was the only reported primary income source for 51 subjects. (See Table A5A) This means that of the 108 subjects with reported income sources, 67 (52.88) received as their primary financial source some form of income assistance (Welfare, Social Security, SSI, Pension) at some point during the time frame of the study. Given the degree of disability which tends to be associated with this population, we would expect the latter figure to be higher. Income source information in the Washington/Idaho state study indicates that a minimum of $64 \%$ of their aftercare subjects received some form of income support within a year of discharge from 
the state hospital.

TABLE A5: PRIMARY INCOME SOURCE DISTRIBUTION

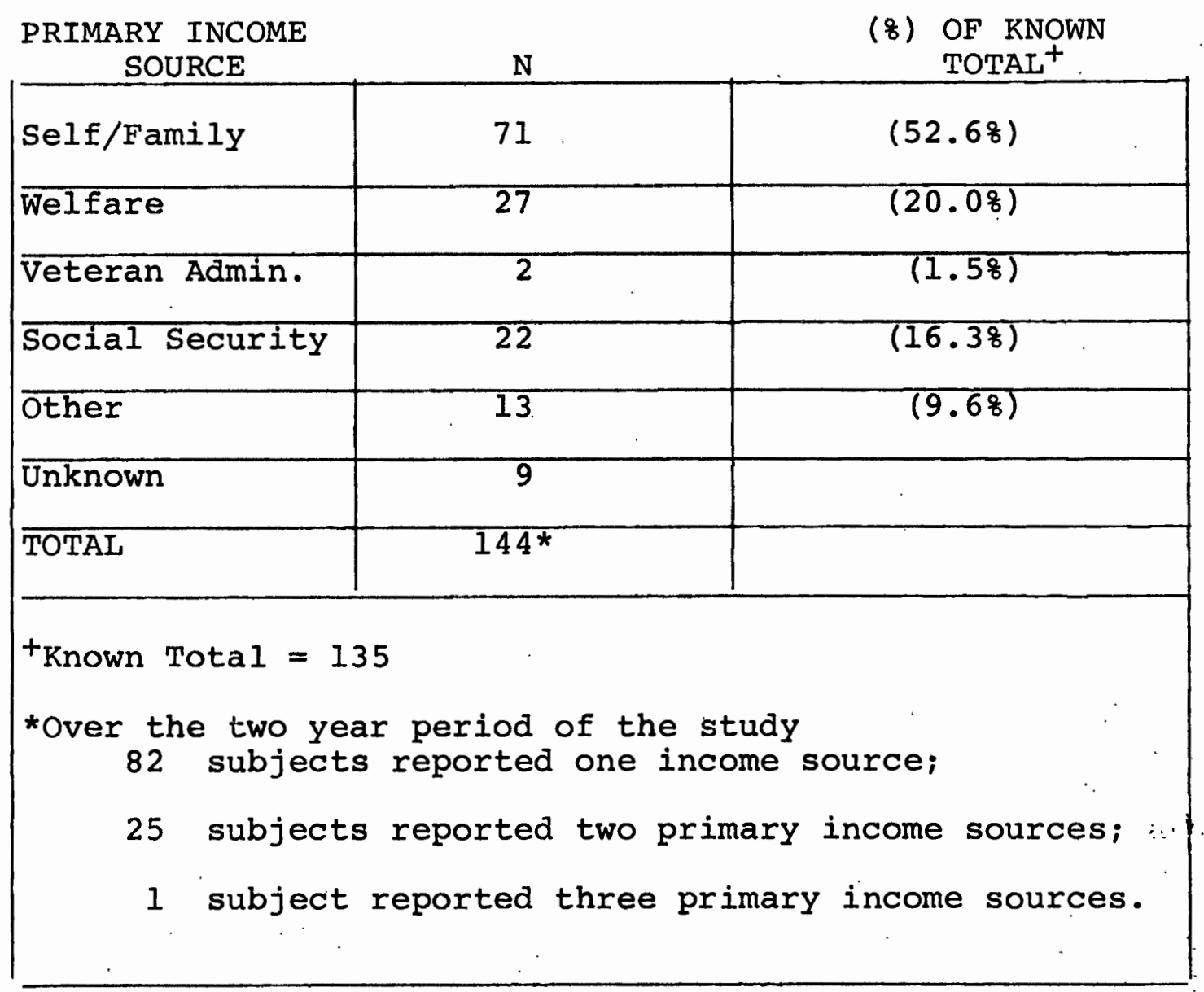


TABLE A5A: DISTRIBUTION OF SUBJECTS WITH ONLY ONE REPORTED PRIMARY INCOME SOURCE

PRIMARY INCOME

SOURCE

$\mathrm{N}$

\begin{tabular}{|l|c|c|}
\hline Self/Family & 51 & $(62.2 \%)$ \\
\hline Welfare & 7 & $(8.5 \%)$ \\
\hline Veteran Admin. & 1 & $(1.2 \%)$ \\
\hline Social Security & 14 & $(17.0 \%)$ \\
\hline Other & 9 & $(11.0 \%)$ \\
\hline TotaL & 82 & $(100.0 \%)$ \\
\hline
\end{tabular}


Gross Family Income: The median family income for the study population is $\$ 2,762$ which is just below the 1976 poverty level $(\$ 2,800)$ for a single member family, and considerably below the 1975 estimated Washington County per capita income of $\$ 5,761$. However, the figure is comparable to the Washington State aftercare study population median income figure of $\$ 2,805$.

TABLE A6: DISTRIBUTION OF GROSS FAMILY INCOME GROSS FAMILY INCOME $\mathrm{N}$

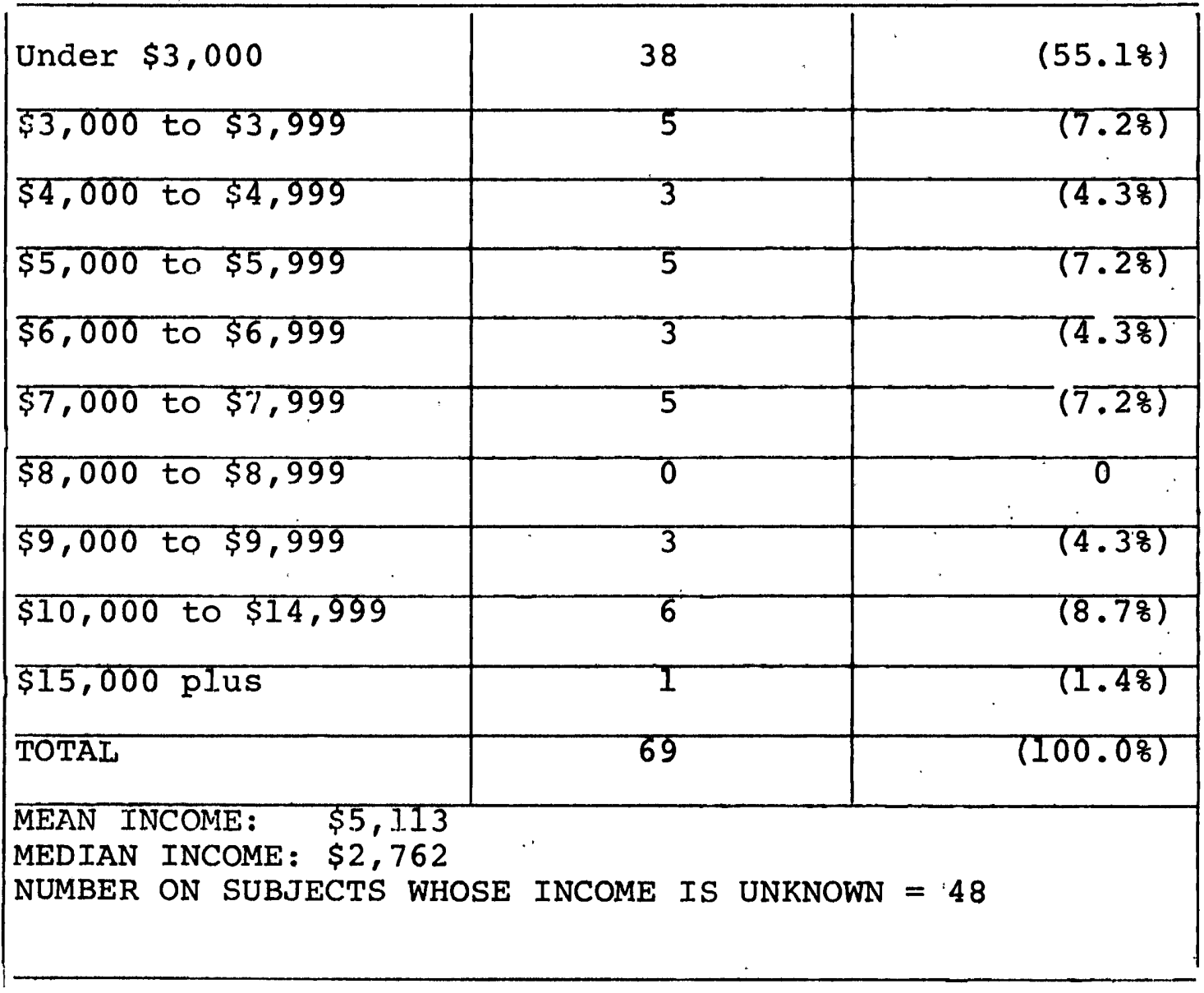


Residence: The study population tends to be quite mobile. During the two-year study period, $55.6 \%$ of the subjects incurred at least one Dammasch hospitalization in which they were admitted from or discharged to a county other than washington County. While in the county, 95.5\% of the subjects resided within the Tualatin Valley (see map 1), an area which also contains $89 \%$ of Washington County's estimated 215,000 population. Table A7A compares the geographic distribution of the study population with that of the general population. Analysis of this table indicates that a proportionately higher number of subjects live in the valley, and in, particularly the west valley area, than would be expected. Additionally, a proportionately low number of subjects live in the more rural areas outside of the valley. 
TABLE A7: DISTRIBUTION OF LAST KNOWN RESIDENCE

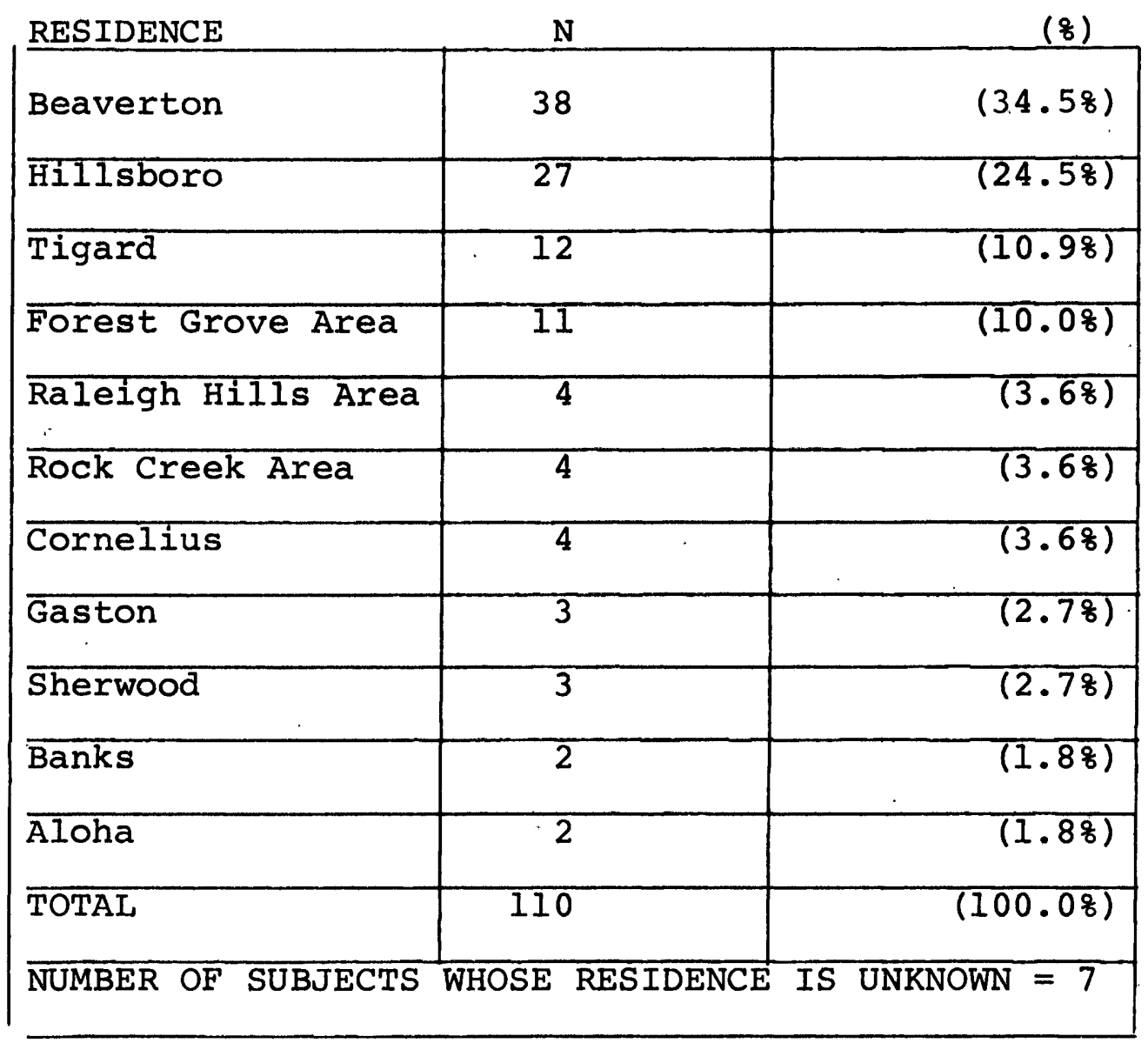

TABLE A7A: POPULATION DISTRIBUTION COMPARISON

GEOGRAPHIC

AREA
(8) $\mathrm{OF}$

STUDY SAMPLE

(8) OF

STUDY SAMPLE

95.58

$(57.2 \%)$

(37.38)

$4.5 q$ COUNTY POPUIATION

$86 \%$

(718)

(18\%)

118 
Section 2: Clinical Characteristics

Diagnosis: Fifty-nine percent of the subjects are diagnosed as having psychotic disorders. Alcohol or drug disorders is the primary disorder associated with $20.5 \%$ of the study population and another $20.5 \%$ of the subjects have mental and emotional disorders spread over several other diagnostic categories. 5

\section{POPULATION CLINICAL PROFILE TABLES}

TABLE BI: PRIMARY DIAGNOSIS DISTRIBUTION

\begin{tabular}{|l|c|c|}
\hline DIAGNOSIS CATEGORY & N & $(8)$ \\
\hline Psychotic & 69 & $(59.08)$ \\
\hline Alcohol/Drug & $20 / 4$ & $(20.58)$ \\
\hline Other & 24 & $(20.58)$ \\
\hline TOTAL & 117 & $(100.08)$ \\
\hline
\end{tabular}

$5_{\text {The source used to identify the individual diagnoses }}$ appropriate for each category was the Oregon Community Mental. Health Programs Data Reporting Procedures Manual, Mental Health Division, Department of Human Resources, Computer Services Unit: Salem Oregon, 1977. 
Dammasch Admissions: During the two year time frame of the study, 66.78 of the subjects incurred two or more admissions to Dammasch State Hospital, with 2.2 as the average number of admissions. Two subjects had a high of 6 admissions and 39 had only one admission. $30 \%$ of the population had no hospital admissions prior to July 1, 1978 (see Table B2), but the study population as a whole had 3.8 life-time Dammasch hospitalizations.

TABLE B2: DISTRIBUTION OF ADMISSIONS TO

DAMMASCH STATE HOSPITAL $(7 / 1 / 76$ to $6 / 31 / 78)$

\begin{tabular}{|c|c|r|} 
NUMBER OF ADMISSIONS & $\mathrm{N}$ & $(\%)$ \\
\hline 1 & 39 & $(33.3 \%)$ \\
\hline 2 & 45 & $(38.5 \%)$ \\
\hline 3 & 16 & $(13.78)$ \\
\hline 4 & 11 & $(9.4 \%)$ \\
\hline 5 & 4 & $(3.4 \%)$ \\
\hline 6 & 2 & $(1.7 \%)$ \\
\hline TOTAL & 117 & $(100.0 \%)$ \\
\hline AVERAGE NUMBER OF ADMISSIONS $=2.2$ & \\
\hline
\end{tabular}


TABLE B2A: DISTRIBUTION OF ADMISSIONS TO

DAMMASCH STATE HOSPITAL -- LIFE TIME

NUMBER OF ADMISSIONS

N

(q)

\begin{tabular}{|c|c|c|}
\hline 2 & 39 & $(33.38)$ \\
\hline 3 & 30 & $(25.6 \%)$ \\
\hline 4 & 20 & $(17.18)$ \\
\hline 5 & 14 & $(12.08)$ \\
\hline 6 & 3 & $(2.68)$ \\
\hline 7 & 5 & $(4.38)$ \\
\hline 8 & 1 & $(.98)$ \\
\hline 9 & 1 & $(.98)$ \\
\hline 11 . & 1 & $(.98)$ \\
\hline 14 & 1 & $(.98)$ \\
\hline 15 & 1 & $(.9 \%)$ \\
\hline 19 & 1 & $(.9 \%)$ \\
\hline TOTAL & 117 & $(100.0 \%)$ \\
\hline AVERAGE NUMBER OF ADMISS & $I O N S=3.8$ & \\
\hline MEDIAN NUMBER OF ADMISSI & ONS $=3$ & \\
\hline
\end{tabular}


Hospital Days: The majority of the subjects (53\%) spent less than 61 days at Dammasch State Hospital. During the two year time period, 18 (15.4\%) individuals exceeded 180 days and 6 of these subjects were hospitalized for over one year.

TABLE B3: DISTRIBUTION OF TOTAL DAYS IN HOSPITAL $(7 / 1 / 76$ to $8 / 31 / 78)$

DAYS IN HOSPITAL $\mathrm{N}$

$(8)$

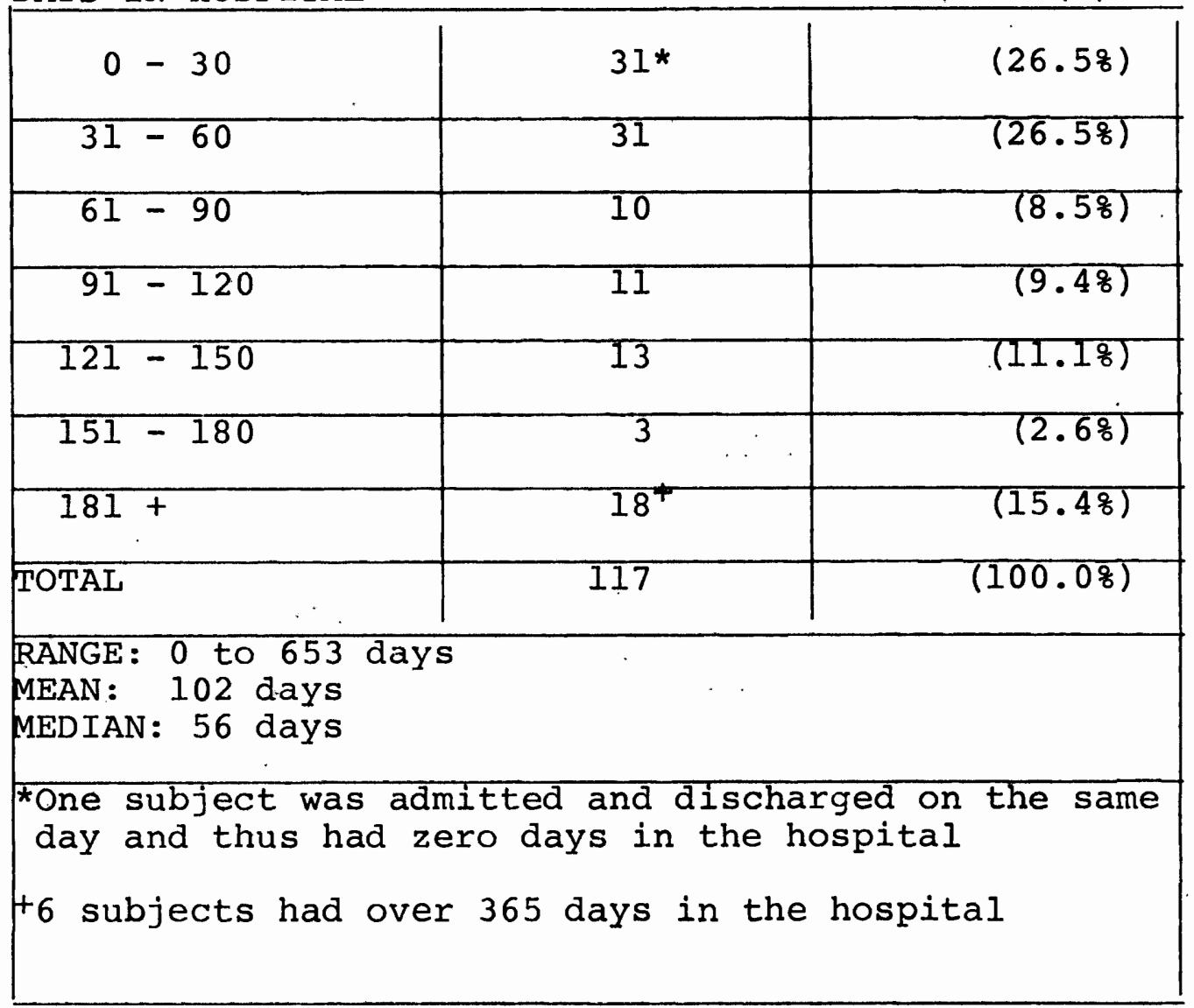


Commitment Type: A total of 253 Dammasch hospital admissions were incurred by the study group. The majority (69.68) of these admissions were voluntary; 20.98 of the admissions were court commitments and 8.38 were emergency or detention warrant commitments. Three admissions had no reported commitment type (see Table B4). In all, 34 subjects were under court commitment at some time during the study period.

TABLE B 4: DISTRIBUTION OF COMMITMENT TYPES

COMMITMENT TYPE
\begin{tabular}{|l|c|l|}
\hline VOLUNTARY & 176 & $(69.6 \%)$ \\
\hline COURT COMMITMENT & 53 & $(20.98)$ \\
\hline EMM. CARE. & 19 & $(7.58)$ \\
\hline DET. WARR & 2 & $(: 8 \%)$ \\
\hline UNKNOWN & 3 & $(1.2 \%)$ \\
\hline TOTAL. & 253 & $(100 \%)$ \\
\hline
\end{tabular}

TABLE B4A: SUBJECTS WITH AT LEAST ONE COURT COMMITMENT DURING STUDY PERIOD

\begin{tabular}{|l|l|l|}
\hline COMMITMENT TYPE & N & $(8)$ \\
\hline OTHER & 31 & $(26.5 \%)$ \\
\hline TOTAL & 86 & $(73.5 \%)$ \\
\hline
\end{tabular}


Section 3: Service Utilization Characteristics

Services Coordination: Aftercare services coordination was utilized by 57 subjects. As would be expected, a high percentage (93.5\%) of the court committed subjects received this service. However, a relatively low proportion (32.6\%) of the non-court committed subjects were clients.

TABLE CI: UTILIZATION OF SERVICES COORDINATION

COURT
\begin{tabular}{|l|cc|ccc|cc|} 
COMMITTED & \multicolumn{2}{c}{$\begin{array}{l}\text { USED SERVICES } \\
\text { COORDINATION }\end{array}$} & \multicolumn{2}{c|}{ DID NERVICES } & COORDINATION & \multicolumn{2}{c|}{ TOTAL } \\
\hline & N & $(8)$ & N & $(8)$ & $(8)$ & N & $(8)$ \\
\hline YES & 29 & $(93.5 \%)$ & $2 *$ & $(6.5 \%)$ & 31 & $(100 \%)$ \\
\hline NO & 28 & $(32.6 \%)$ & 58 & $(67.4 \%)$ & 86 & $(100 \%)$ \\
\hline TOTAL & 57 & $(48.7 \%)$ & 60 & $(51.3 \%)$ & $117(100 \%)$ \\
\hline
\end{tabular}

*Both subjects were residents of another county while under Court Commitment 
Subcontract Agency Utilization: Washington County Community Mental Health subcontract agencies provided treatment services to $57(48.78)$ subjects. An additional 5 subjects who did not obtain services in Washington County were treated through one of Multnomah County's mental health clinics.

TABLE C2: UTILIZATION OF SUBCONTRACT AGENCIES*

\begin{tabular}{|c|c|c|}
\hline AGENCY & NUMBER OF SUBJECTS & (8) UNDUPLICATED TOTAL \\
\hline LFS & 5 & $(8.1)$ \\
\hline MFS & 4 & $(6.58)$ \\
\hline TVW & 21 & $(33.98)$ \\
\hline $\begin{array}{l}\text { CEDAR HILLS } \\
\text { (INPATIENT) }\end{array}$ & 1 & $(1.68)$ \\
\hline TVMHC & 44 & $(718)$ \\
\hline MCMHC & 13 & $(218)$ \\
\hline $\begin{array}{l}\text { DUPLICATED } \\
\text { TOTAL }\end{array}$ & 88 & . \\
\hline $\begin{array}{l}\text { UNDUPLICATED } \\
\text { TOTAL }\end{array}$ & 62 ** & \\
\hline
\end{tabular}

*Client services were not provided, to this population, by NARA, Centro Culture and WCMHP (Drug)

*57 SUBJECTS WERE SERVED BY WASHINGTON COUNTY SUB-CONTRACT AGENCIES 
The most extensively used subcontract agency was Tualatin Valley Mental Health Center which treated 44 subjects. Tualatin Valley Workshop Inc. was utilized by 21 subjects and a duplicated total of ten individuals received treatment through one or more of the remaining three Washington County service providers. Multnomah County provicied aftercare treatment to 13 subjects during the two-year study period.

The majority of the subjects received services (while in washington County) through only one mental health agency. Fourteen subjects were served by two agencies and two individuals were clients of three subcontractors.

TABLE C3: NUMBER OF AGENCIES UTILIZED NUMBER $\mathrm{N}$

$(8)$

\begin{tabular}{|c|c|c|}
\hline 0 & 60 & $(51.38)$ \\
\hline 1 & 41 & $(35.08)$ \\
\hline 2 & 14 & $(12.08)$ \\
\hline 3 & 2 & $(1.78)$ \\
\hline TOTAL & 117 & $(100.08)$ \\
\hline
\end{tabular}


Duration of Community Treatment: The average length of stay in treatment for the 57 subjects who received services through one or more of the County's mental health subcontract agencies was 270 days. A sizable portion (33.3\%) of these individuals accumulated over 360 community treatment days during the two-year study period.

TABLE C4: DURATION OF COMMUNITY TREATMENT

\begin{tabular}{|c|c|c|}
\hline DAYS & $\mathrm{N}$ & $(8)$ \\
\hline 1 to 60 days & 17 & $(29.88)$ \\
\hline 61 to 120 days & 6 & $(10.58)$ \\
\hline 121 to 180 days & 4 & $(7.08)$ \\
\hline 181 to 240 days & 6 & $(10.58)$ \\
\hline 241 to 300 days & 3 & $(5.38)$ \\
\hline 301 to 360 days & 2 & $(3.58)$ \\
\hline 360 plus & 19 & $(33.38)$ \\
\hline TOTAL & 57 & $(100.08)$ \\
\hline $\begin{array}{l}\text { RANGE : } \\
\text { MEAN : } \\
\text { MEDIAN : }\end{array}$ & 729 & \\
\hline
\end{tabular}


Medication: A review of client clinical records revealed that of the 57 subjects receiving treatment through subcontract agencies, $44(77.2 \%)$ were prescribed some type of medication while in treatment. Thirty-nine of the subjects had their medication monitored through Tualatin Valley Mental Health Center (see Table C5). The case files of another five subjects showed that they were receiving medications while clients of Tualatin Valley Workshop Inc.

TABLE C5: CLIENTS REPORTED ON MEDS (TVMHC)

\begin{tabular}{|l|c|c|}
\hline ON MEDS & N & $(\%)$ \\
\hline Yes & 39 & $(88.6 \%)$ \\
\hline NO & 5 & $(11.4 \%)$ \\
\hline TOTAL & 44 & $(100.0 \%)$ \\
\hline
\end{tabular}


Condition of Treatment Termination: An attempt was made during the review of client files to ascertain the extent to which treatment termination occurred with/without the therapist's approval or without the therapist's knowledge. Unfortunately, this type of information was not consistently reported in the subject's case files. Of the 71 treatment terminations, 21 were accompanied by some type of termination statement in the case notes. In an additional 12 cases, no termination statement was provided, but the disposition section of the CL-1 (Client Information Form) was completed. In very few instances was it possible to ascertain from the information provided if the therapist approved of the termination or even had knowledge of the termination until after the event occurred. Basically, the only information that could be consistently obtained was who instigated the termination. Table $\underline{6} 6$ presents this information. Summarizing from the Table, there were 33 terminations in which some aspect of the event is "known". Of the 33 "known" terminations, 5 were clinic instigated, 18 were instigated by the client, 5 were mutually agreed upon by client and therapist, and five clients left treatment because of rehospitalization. 
TABLE C6: TYPES OF TREATMENT TERMINATION

\begin{tabular}{|c|c|c|}
\hline TERMINATION TYPE & NUMBER OF SUBJECTS & $\left(\frac{\%}{8}\right)$ \\
\hline CLINIC INSTIGATED & 5 & $(15.2 \%)$ \\
\hline CLIENT INSTIGATED & 18 & $(54.5 \%)$ \\
\hline MUTUAL AGREEMENT & 5 & $(15.28)$ \\
\hline REHOSPITALI ZED & 5 & $(15.2 \%)$ \\
\hline TOTAL & 33 & $(100 \%)$ \\
\hline UNKNOWN & 38 & . \\
\hline
\end{tabular}




\section{Part Two - Differentiating the Chronic Aftercare population}

In the following sections we will examine the relationship between various study population characteristics and 1. The number of Dammasch State Hospital admissions incurred between June 31, 1976 and July 1, 1978 .

2. Total days spent as an inpatient at the State Hospital during the study period.

3. Primary diagnosis.

4. Hospital commitment type.

Section 1: The Relationship Between Selected Subject Characteristics and the Number of Dammasch State Hospital Admissions Incurred Between June 31,1976 and July $1,1978$.

Age: Examination of the data indicates that as the number of hospitalizations increases, age tends to decrease. This relationship is revealed through examination of the median ages of the one, two, and three plus admissions groups which are 41.4 years, 36.4 years, and 34.3 years respectively. If number of admissions is assumed to be a reliable indicator of severity, it could be said that the younger portions of the research population tend to manifest more severely disabling emotional disturbances than than their older counterparts. 
RELATIONSHIPS BETWEEN SELECTED SUBJECT CHARACTERISTICS AND THE NUMBER OF HOSPITAL ADMISSIONS INCURRED BETWEEN $7 / 1 / 76$ AND $6 / 31 / 78$

TABLE DIA: AGE AND NUMBER OF HOSPITAL ADMISSIONS

\begin{tabular}{|c|c|c|c|c|}
\hline $\begin{array}{l}\text { CHARACTERISTIC: } \\
\text { AGE }\end{array}$ & $\begin{array}{ll}1 & A D M . \\
N & (8)\end{array}$ & $\begin{array}{ll}2 & \text { ADM. } \\
N & (z) \\
\end{array}$ & $\begin{array}{l}3 \text { ADM. + } \\
N \quad(8)\end{array}$ & $\begin{array}{l}\text { TOTAL } \\
\mathrm{N}(\%) \\
\end{array}$ \\
\hline $12-17$ years & 0 & 0 & $1(3)$ & $1(.9)$ \\
\hline $18-44$ years & $21(53.8)$ & $32(71.1)$ & $25(75.8)$ & $78(66.7)$ \\
\hline $45-64$ years & $13(33.3)$ & $10(22.2)$ & $6(18.2)$ & $29(24.8)$ \\
\hline years & $5(12.8)$ & $3(6.7)$ & $I(3)$ & $9(7.7)$ \\
\hline TOTAL & $39(100)$ & $45(100)$ & $33(100)$ & $117(100)$ \\
\hline$\overline{\text { MEDIAN } \mathrm{AGE}}$ & $41.4 \mathrm{yr}$. & $36.4 \mathrm{yr}$ & $34.3 \mathrm{yr}$. & 36 yr. \\
\hline
\end{tabular}


Sex: Women tend to be over represented in the single admission group while the double admission group has a rather high proportion of males. The ratio of men to women in the three plus admission group approaches what would be expected given the sex break down of study population.

TABLE DIB: SEX AND NUMBER OF HOSPITAL ADMISSIONS

$\begin{array}{llllll}\text { CHARACTERISTIC: } & 1 \text { ADM. } & 2 \text { ADM. } & 3 \text { ADM. } & \text { TOTAL } \\ \text { SEX } & \mathrm{N}(8) & \mathrm{N}(\mathrm{z}) & \mathrm{N}(\mathrm{z}) & \mathrm{N}(\mathrm{z})\end{array}$

\begin{tabular}{|l|r|c|c|c|}
\hline Male & $15(38.5)$ & $29(64.4)$ & $17(51.5)$ & $61(52.1)$ \\
\hline Female & $24(61.5)$ & $16(35.6)$ & $16(48.5)$ & $56(47.9)$ \\
\hline AverAL & $39(100)$ & $45(100)$ & $33(100)$ & $117(100)$ \\
\hline
\end{tabular}

Marital Status: A review of Table DlC shows that as the number of hospital admissions increases, the proportion of married subjects in each of the three admissions categories decreases. The inverse relationship is true for the single subjects. Thus, it seems that being married is associated with lower hospital readmission rates while being single is associated with higher rates. There is little difference in the proportion of subjects in the other marital categories when compared across admission groups. 
TABLE DIC: MARITAL STATUS AND NUMBER OF HOSPITAL ADMISSIONS

\begin{tabular}{l|c|c|c|c|} 
CHARACTERISTIC: & \multicolumn{1}{c}{$\begin{array}{l}\text { ADM. } \\
\text { MARITAL STATUS }\end{array}$} & $\begin{array}{c}2 \text { ADM. } \\
\mathrm{N}(8)\end{array}$ & $\begin{array}{c}3 \text { ADM.+ } \\
\mathrm{N}(8)\end{array}$ & $\begin{array}{l}\text { TOTAL } \\
\mathrm{N}(8)\end{array}$ \\
\hline Single & $9(23.1)$ & $13(28.9)$ & $15(45.5)$ & $37(31.6)$ \\
\hline Married & $16(41.0)$ & $16(35.6)$ & $4(12.1)$ & $36(30.8)$ \\
\hline Divorced & $10(25.6)$ & $10(22.2)$ & $11(33.3)$ & $31(26.5)$ \\
\hline Separated & $2(5.1)$ & $3(6.7)$ & $2(6.1)$ & $7(6)$ \\
\hline Widowed & $2(5.1)$ & $3(6.7)$ & $1(3)$ & $6(5.1)$ \\
\hline TOTAL & $39(100)$ & $45(100)$ & $33(100)$ & $117(100)$ \\
\hline
\end{tabular}

Race: A review of Table DlD indicates that there tends to be no relationship between race and frequency of hospital admissions.

TABLE DID: RACE AND NUMBER OF HOSPITAL ADMISSIONS

\begin{tabular}{|c|c|c|c|c|}
\hline $\begin{array}{l}\text { CHARACTERISTIC: } \\
\text { RACE }\end{array}$ & $\begin{array}{ll}1 & A D M . \\
N & (z)\end{array}$ & $\begin{array}{ll}2 & A D M . \\
\mathrm{N} & (8)\end{array}$ & $\begin{array}{l}3 \text { ADM. }+ \\
N(8)\end{array}$ & $\begin{array}{l}\text { TOTAL } \\
\mathrm{N}(\%)\end{array}$ \\
\hline White & $36(92.3)$ & $43(95.6)$ & $30(90.9)$ & $109(93.2)$ \\
\hline other & $3(7.7)$ & $2(4.4)$ & $3(9.1)$ & $8(6.8)$ \\
\hline TOTAL & $39(100)$ & $45(100)$ & $33(100)$ & $117(100)$ \\
\hline
\end{tabular}


Primary Income Source: The majority of the subjects in the one and two admission categories derived their primary income support through self-earnings or family assistance. In the three plus admission group, 54.28 of the subjects received their primary support through sources other than self/family.

TABLE DIE: PRIMARY INCOME SOURCE AND NUMBER OF HOSPITAL ADMISSIONS

$\begin{array}{lllll}\text { CHARACTERISTIC: } & \text { I ADM. } & 2 \text { ADM.. } & 3 \text { ADM.+ } & \text { TOTAL } \\ \text { PRIMARY INCOME } & \mathrm{N}(8) & \mathrm{N}(\mathrm{z}) & \mathrm{N}(8) & \mathrm{N}(\mathrm{z})\end{array}$

\begin{tabular}{|l|c|c|c|c|}
\hline Self/Family & $20(54.1)$ & $30(60)$ & $22(45.8)$ & $72(53.3)$ \\
\hline Welfare & $6(16.2)$ & $7(14)$ & $14(29.2)$ & $27(20)$ \\
\hline Veteran Admin. & 0 & $1(2)$ & $1(2.1)$ & $2(1.5)$ \\
\hline Social Security & $6(16.2)$ & $8(16)$ & $8(16.7)$ & $22(16.3)$ \\
\hline Other & $5(13.5)$ & $4(8)$ & $3(6.2)$ & $12(8.9)$ \\
\hline TOTAL & $37(100)$ & $50(100)$ & $48(100)$ & $135(100)$ \\
\hline Income Source information was not obtained on 9 clients
\end{tabular}


Gross Family Income: There is little difference in the income levels between the one admission and two admission groups. However, the three plus admission group is made up of a relatively higher percentage (62.5\%) of subjects with incomes under $\$ 3,000$.

TABLE DIF: GROSS FAMILY INCOME AND NUMBER OF HOSPITAL ADMISSIONS

$\begin{array}{lllll}\text { CHARACTERISTIC: } & \text { I ADM. } & 2 \text { ADM. } & 3 \text { ADM. } & \text { TOTAL } \\ \text { GROSS FAMILY } & \mathrm{N}(z) & \mathrm{N}(z) & \mathrm{N}(z) & \mathrm{N}(\mathrm{z}) \\ \text { INCOME } & & \end{array}$

\begin{tabular}{|c|c|c|c|c|}
\hline Under $\$ 3,000$ & $9(52.9)$ & $14(50)$ & $15(62.5)$ & $38(55.1)$ \\
\hline$\$ 3,000$ to $\$ 5,999$ & $4(23.5)$ & $6(21.4)$ & $3(12.5)$ & $13(18.8)$ \\
\hline$\$ 6,000$ to $\$ 8,999$ & $2(11.8)$ & $4(14.3)$ & $2(8.3)$ & $8(11.6)$ \\
\hline$\$ 9,000+$ & $2(11.8)$ & $4(14.3)$ & $4(16.7)$ & $10(14.5)$ \\
\hline TOTAL & $17(100)$ & $28(100)$ & $24(100)$ & $69(100)$ \\
\hline MEDIAN & $\$ 2,999$ & $\$ 3,500$ & $\$ 2,499$ & $\$ 2,762$ \\
\hline
\end{tabular}


Residence: The data indicates that there tends to be no relationship between location of residence and hospital admission rates.

TABLE DIG: RESIDENCE AND NUMBER OF HOSPITAL ADMISSIONS

\begin{tabular}{|c|c|c|c|c|}
\hline $\begin{array}{l}\text { CHARACTERISTIC: } \\
\text { RESIDENCE }\end{array}$ & $\begin{array}{ll}1 & A D M . \\
N & (8)\end{array}$ & $\begin{array}{ll}2 & \text { ADM. } \\
\mathrm{N} & (8)\end{array}$ & $\begin{array}{ll}3 & A D M .+ \\
N & (8)\end{array}$ & $\begin{array}{l}\text { TOTAL } \\
\mathrm{N}(8)\end{array}$ \\
\hline Beaverton Area & $12(34.3)$ & $14(32.6)$ & $12(37.5)$ & $38(34.5)$ \\
\hline Hillsboro & $8(22.9)$ & $12(27.9)$ & $7(21.9)$ & $27(24.5)$ \\
\hline Tigard & $4(11.4)$ & $5(11.6)$ & $3(9.4)$ & $12(10.9)$ \\
\hline Forest Grove & $6(17.1)$ & $4(9.3)$ & $1(3.1)$ & $11(10)$ \\
\hline Raleigh Hills & $2(5.7)$ & $1(2.3)$ & $1(3.1)$ & $4(3.6)$ \\
\hline Rock Creek & 0 & 0 & $4(12.5)$ & $4(3.6)$ \\
\hline Cornelius & $\overline{0}$ & $3(7)$ & $1(3.1)$ & $4(3.6)$ \\
\hline Gaston & $1(2.9)$ & $1(2.3)$ & $1(3.1)$ & $3(2.7)$ \\
\hline Sherwood & $1(2.9)$ & $2(4.7)$ & 0 & $3(2.7)$ \\
\hline Banks & $1(2.9)$ & 0 & $1(3.1)$ & $2(1.8)$ \\
\hline Aloha & 0 & $1(2.3)$ & $I(3.1)$ & $2(1.8)$ \\
\hline TOTAL & $35(100)$ & $43(100)$ & $32(100)$ & $110(100)$ \\
\hline
\end{tabular}


Primary Diagnosis: Less than half (43.6\%) of the subjects. with only one admission are labled psychotic while 62.28 of the 2 admission and 72.28 of the 3 plus admission groups are made up of individuals with this diagnosis. There is a decrease in the proportion of subjects with alcohol and drug disorders as we move from the single to the 3 plus admission group. The proportion of subjects in the "other" diagnostic category shows a drop from the single to double admission groups, but slightly increases in the 3 plus group. In general, these findings indicate that multiple readmissions tend to be more characteristic of subjects diagnosed as psychotic and atypical of those individuals with an alcohol and drug or "other" diagnosis.

TABLE DIH: PRIMARY DIAGNOSIS AND NUMBER OF HOSPITAL ADMISSIONS

\begin{tabular}{|c|c|c|c|c|}
\hline $\begin{array}{l}\text { CHARACTERISTIC: } \\
\text { PRIMARY DIAGNOSIS }\end{array}$ & $\begin{array}{ll}1 & A D M \\
N & (8)\end{array}$ & $\begin{array}{l}2 \text { ADM. } \\
\mathrm{N}(\%)\end{array}$ & $\begin{array}{ll}3 & \text { ADM. }+ \\
N & (8)\end{array}$ & $\begin{array}{l}\text { TOTAL } \\
\mathrm{N}\left(\frac{\%}{8}\right)\end{array}$ \\
\hline Psychosis & $17(43.6)$ & $28(62.2)$ & $24(72.7)$ & $69(59)$ \\
\hline $\bar{A} \& D$ & $11(28.2)$ & $10(22.2)$ & $3(9.1)$ & $24(20.5)$ \\
\hline other & $I I(28.2)$ & $7(15.6)$ & $6(18.2)$ & $24(20.5)$ \\
\hline TOTAL & $39(100)$ & $45(100)$ & $33(100)$ & $117(100)$ \\
\hline
\end{tabular}


Section 2: The Relationship Between Selected Subject Characteristics and Total Days in the Hospital.

Age, Sex and Race: There appears to be no consistent relationship between age, sex, or race and total days spent in the hospital. 

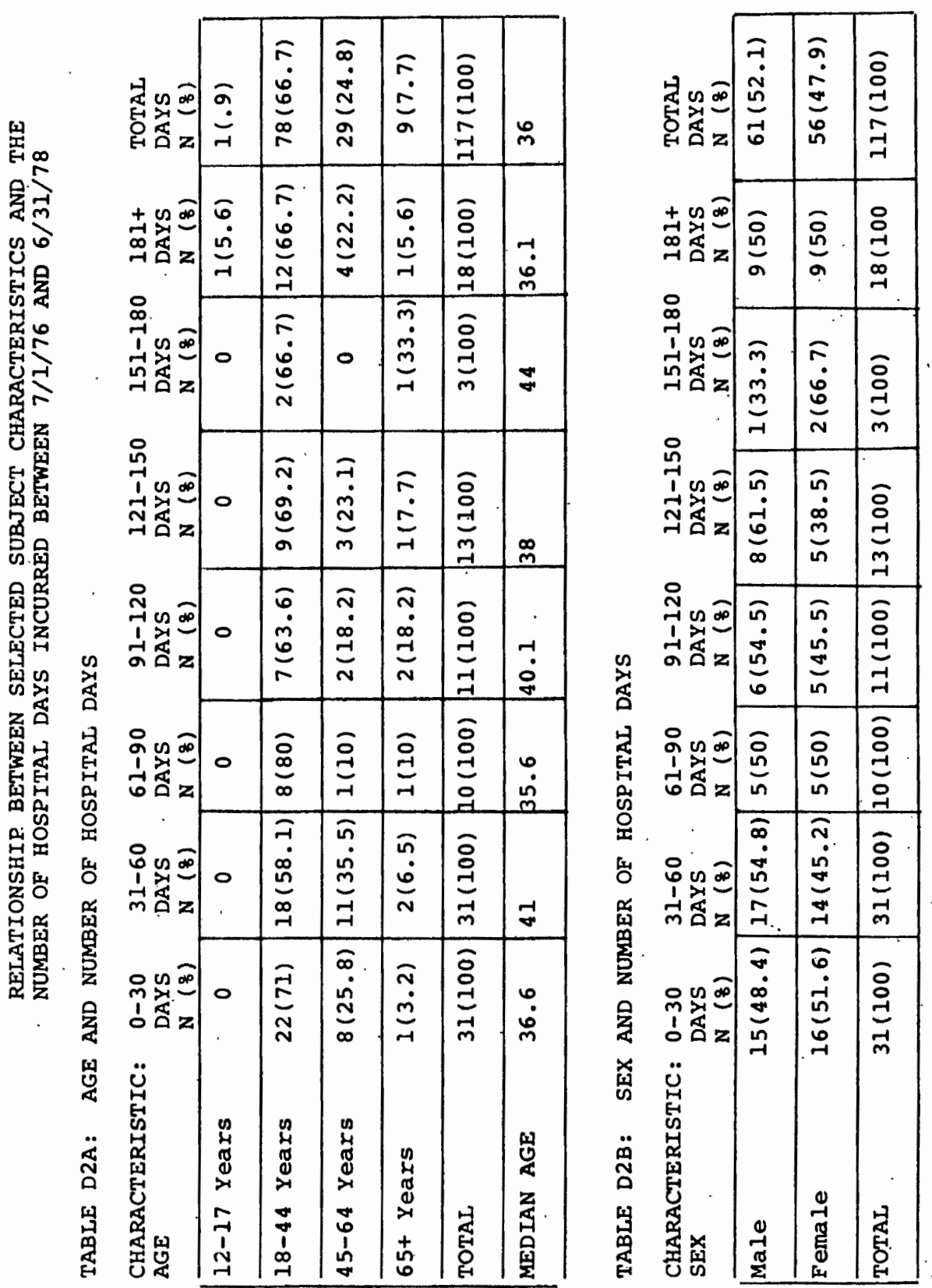


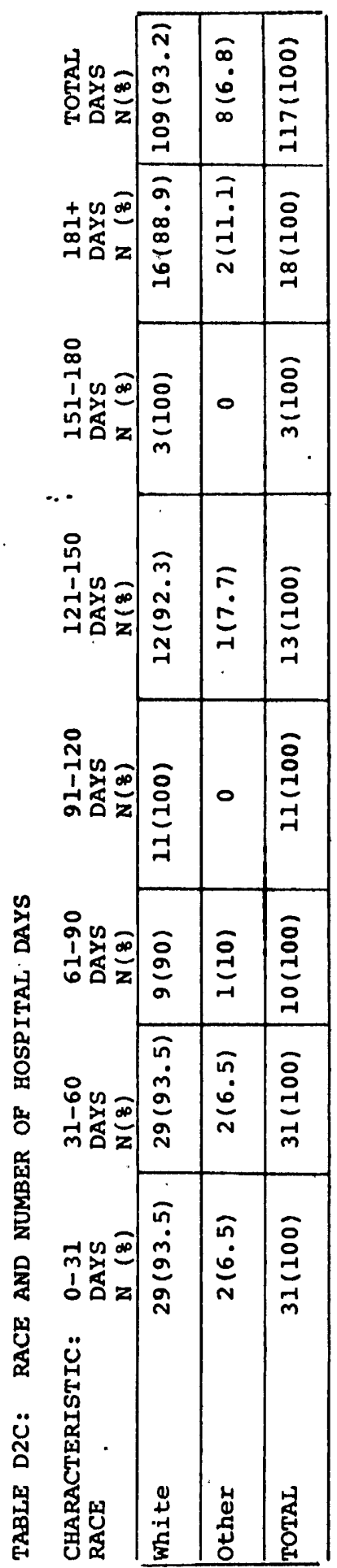


Marital Status: Examining Table D2D, the most interesting statistics are found in the two extreme columns. In the 0 to 30 day column, we see that 54.88 of these subjects are married, 298 are divorced, and just under 138 are single, while at the other end in the 180 plus column, 11.18 are married, 5.68 are divorced, and $66.7 \%$ are single. These figures suggest that longer hospital stays tend to be associated with single individuals while shorter stays are associated with married and to a lesser extent, : divorced subjects. 


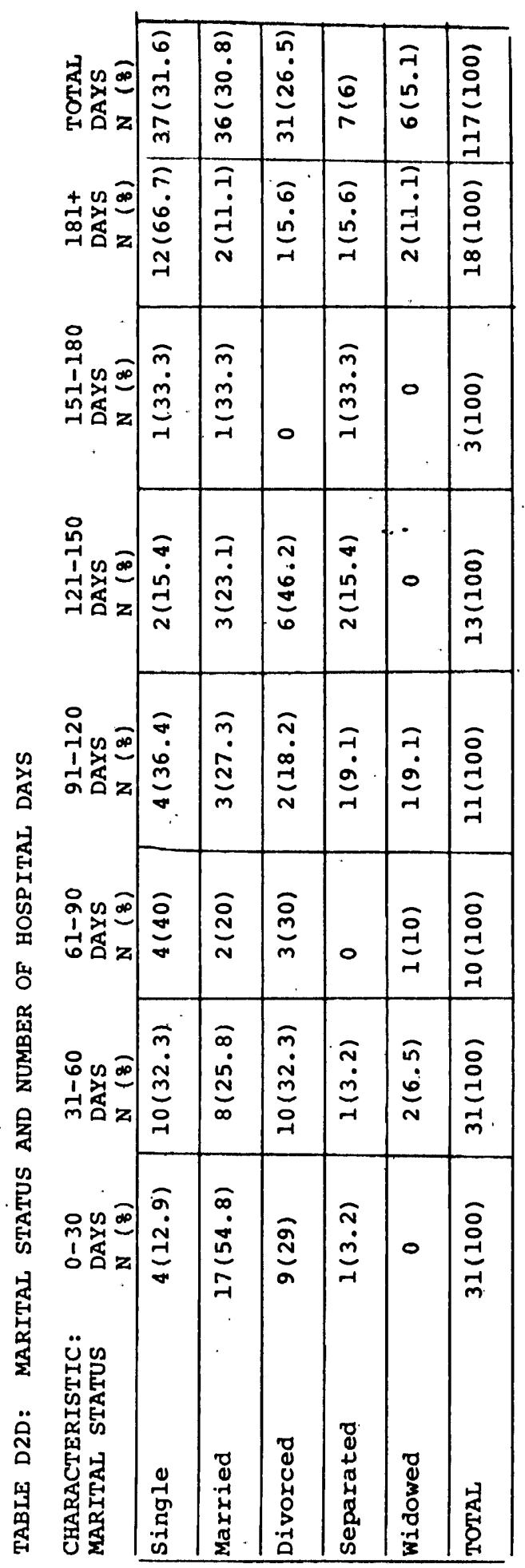


Primary Income Source: It appears that subjects with self/family as the reported primary income source tend to spend slightly fewer days in the hospital than other members of the research population. This finding is most evident through an examination of the "0 to 30 days" column and "181 plus days" column of Table D2E. What we find is that over half (57.18) of the subjects in the first column have as their primary income source self/family, while in the last column the percentage drops to $41.7 \%$. 


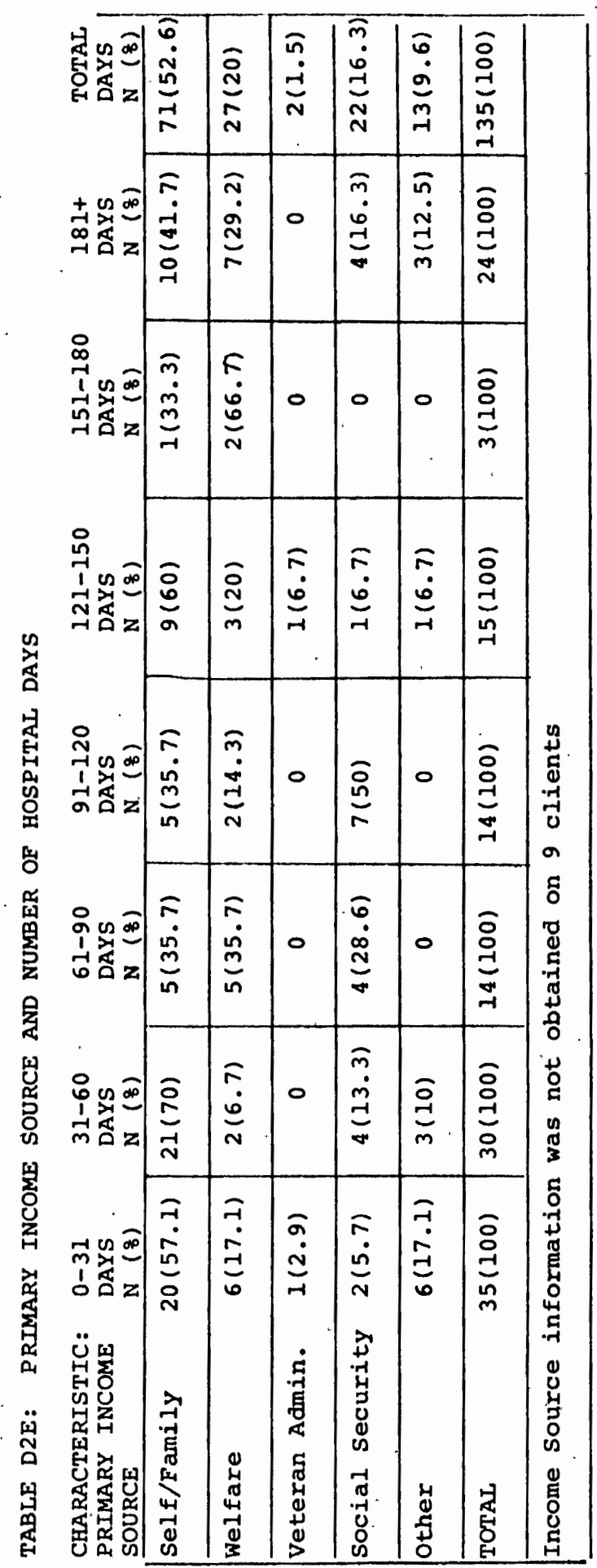


Gross Family Income: Income figures for those subjects with more than 180 days in the hospital show that 76.98 have a gross income under $\$ 3,000$, while only $38.5 \%$ of those with less than 31 hospital days fall into this same income range. This data suggests that subjects with lower gross family incomes tend to spend more days in the hospital. However, it must be pointed out that the data, as displayed in Table D2F does not reveal any consistent relationship between higher income levels and fewer days spent in the hospital. 


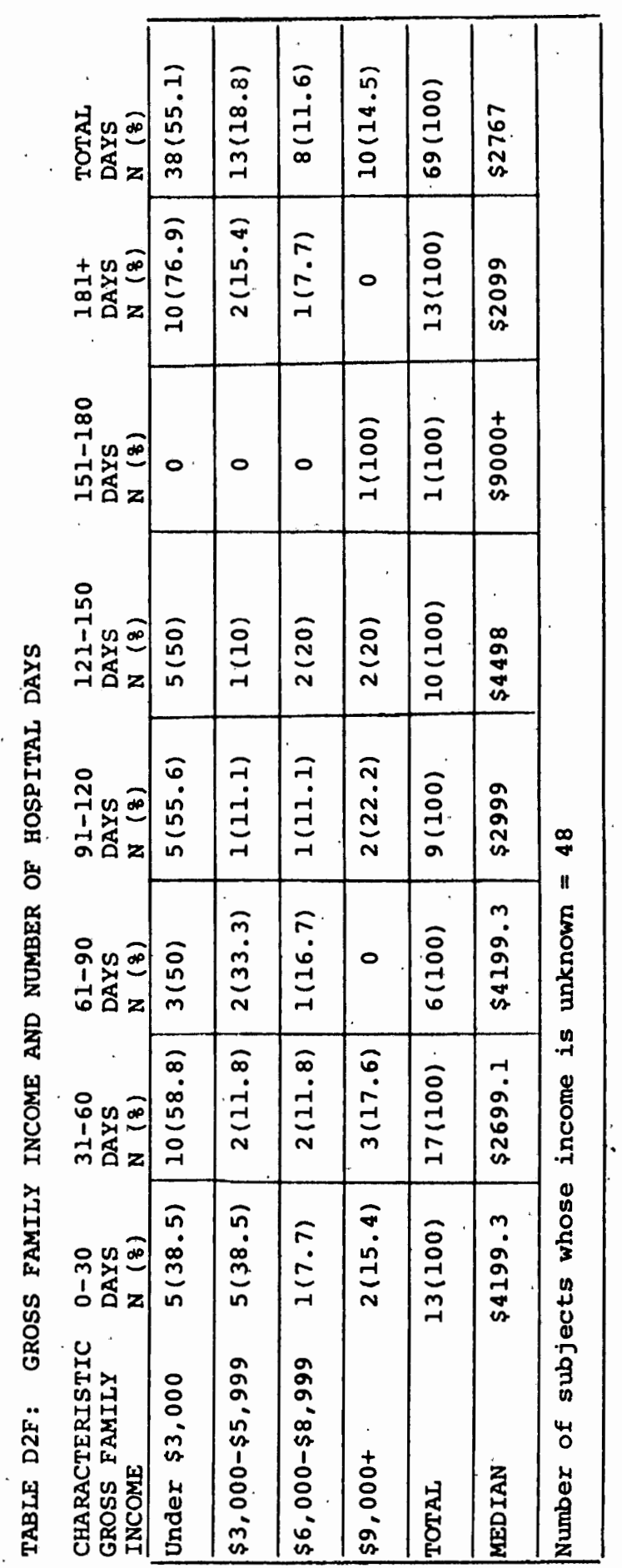


Residence: The information of interest contained in Table D2G is that 61.28 of the subjects who spent more than 180 days in the hospital, tend to live in the Beaverton, Rock Creek, and Raleigh Hills area. 


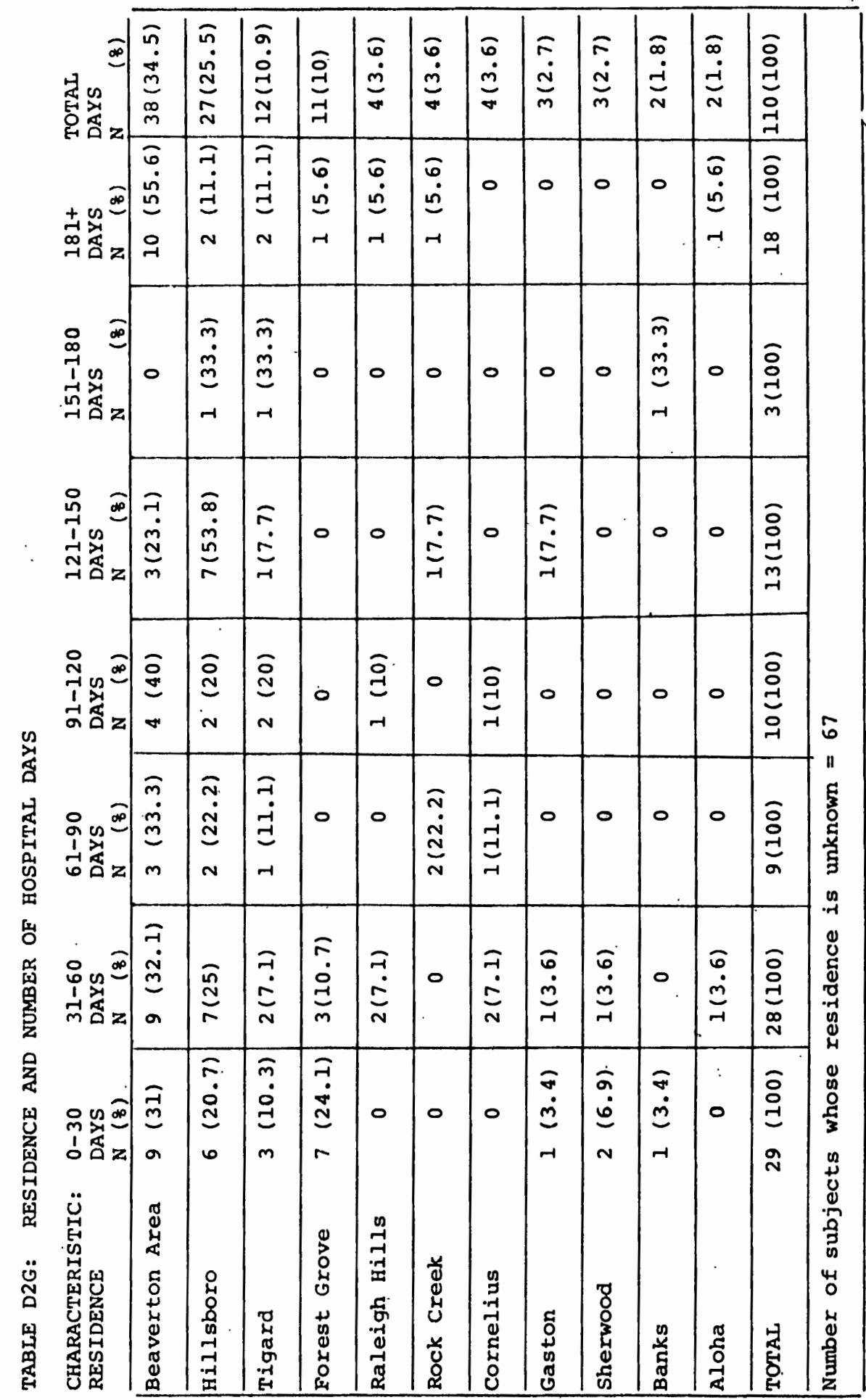


Primary Diagnosis: The data shows that subjects with psychotic disorders tend to stay in the hospital longer than individuals with other types of disorders. High proportions of psychotically disturbed subjects make up the last four hospital day categories, while no alcohol and drug subjects are contained in the last three categories. Finally, while the figures for the "other" diagnostic group are sporatic, there is a tendency for subjects in this category to accumulate more hospital days than those with alcohol and drug disorders, but considerably less days than the psychotic individuals. 


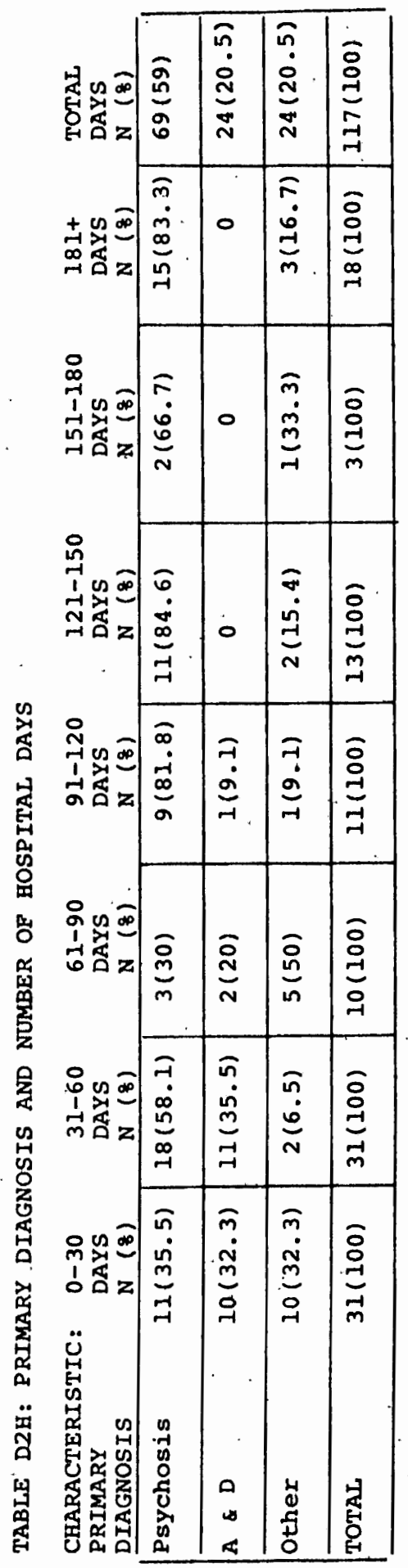


Section 3: The Relationship Between Selected Subject Characteristics and Primary Diagnosis.

Age: Individuals with psychosis-related disturbances tend to be younger than the subjects who comprise the other two categories. There is little difference in age characteristics between the alcohol and drug and "other" diagnostic groups.

\section{THE RELATIONSHIP BETWEEN SELECTED SUBJECT CHARACTERISTICS AND PRIMARY DIAGNOSIS}

TABLE D3A: AGE AND PRIMARY DIAGNOSIS CHARACTERISTIC: PSYCHOSIS AGE

$\mathrm{N}(8)$

$A \& D$

OTHER

TOTAL

N (z)

N ( 8 )

N (응

\begin{tabular}{|l|c|c|c|c|}
\hline $12-17$ Years & 0 & 0 & $1(4.2)$ & $1(.9)$ \\
\hline $18-44$ Years & $50(72.5)$ & $14(58.3)$ & $14(58.3)$ & $78(66.7)$ \\
\hline $45-64$ Years & $12(17.4)$ & $10(41.7)$ & $7(29.2)$ & $29(24.8)$ \\
\hline $65+$ Years & $7(10.1)$ & 0 & $2(8.3)$ & $9(7.7)$ \\
\hline TOTAL & $69(100)$ & $24(100)$ & $24(100)$ & $117(100)$ \\
\hline MEDIAN AGE & 35.9 & 41.1 & 39.2 & 36 \\
\hline
\end{tabular}


Sex: The proportion of males to females in the psychosis group tends to mirror that of the research population. The alcohol and drug group has a rather high proportion of males while the inverse is true of the third group.

TABLE D3B: SEX
$\begin{aligned} & \text { CHARACTERISTIC: } \\
& \text { PSYCHOSIS } \\
& \text { SEX }\end{aligned}$
\begin{tabular}{|l|c|c|c|c|}
\hline N $(8)$ & $\begin{array}{c}\text { A } \& \text { D } \\
\text { N }(8)\end{array}$ & $\begin{array}{c}\text { OTHER } \\
\text { N }(8)\end{array}$ & $\begin{array}{l}\text { TOTAL } \\
\text { N }(8)\end{array}$ \\
\hline Male & $37(53.6)$ & $18(75)$ & $6(25)$ & $61(52.1)$ \\
\hline Female & $32(46.4)$ & $6(25)$ & $18(75)$ & $56(47.9)$ \\
\hline TOTAL & $69(100)$ & $24(100)$ & $24(100)$ & $117(100)$ \\
\hline
\end{tabular}


Marital Status: The alcohol and drug group tends to have a high proportion of its members falling into the married and divorced categories, while relatively few are classified as single. There seems to be little difference between the marital status characteristics of the "other" diagnostic subjects and those of the study population, with the exception that the former has a slightly lower proportion of divorced members than the latter. Compared to the other two diagnostic groups, those subjects with primarily psychotic disorders seem, as a whole, to have more single but less married or divorced individuals.

\begin{tabular}{|c|c|c|c|c|}
\hline $\begin{array}{l}\text { TABLE D3C: MAR } \\
\text { CHARACTERISTIC: } \\
\text { MARITAL STATUS }\end{array}$ & $\begin{array}{l}\text { AL STATUS } \\
\text { PSYCHOSIS } \\
\mathrm{N}(\&)\end{array}$ & $\begin{array}{l}\text { PRIMARY } \\
A \& D \\
N(8) \\
\end{array}$ & $\begin{array}{l}\text { AGNOSIS } \\
\text { OTHER } \\
\mathrm{N}(\%) \\
\end{array}$ & $\begin{array}{l}\text { TOTAL } \\
\mathrm{N}(8)\end{array}$ \\
\hline Single & $26(37.7)$ & $3(12.5)$ & $8(33.3)$ & $37(31.6)$ \\
\hline Married & $18(26.1)$ & $10(41.7)$ & $8(33.3)$ & $36(30.8)$ \\
\hline Divorced & $17(24.6)$ & $9(37.5)$ & $5(20.8)$ & $31(26.5)$ \\
\hline Separated & $5(7.2)$ & $1(4.2)$ & $I(4.2)$ & $7 \cdot(6)$ \\
\hline Widowed & $3(4.3)$ & $1(4.2)$ & $2(8.3)$ & $6(5.1)$ \\
\hline TOTAL & $69(100)$ & $24(100)$ & $24(100)$ & $117(100)$ \\
\hline
\end{tabular}


Race: Whites comprise 1008 of the alcohol and drug group, while the other two diagnostic categories have approximately equal proportions of non-whites.

TABLE D3D: RACE AND PRIMARY DIAGNOSIS

\begin{tabular}{|c|c|c|c|c|}
\hline $\begin{array}{l}\text { CHARACTERISTIC: } \\
\text { RACE }\end{array}$ & $\begin{array}{l}\text { PSYCHOSIS } \\
\mathrm{N}(8)\end{array}$ & $\begin{array}{ll}A & \& \\
N & D \\
N & (8) \\
\end{array}$ & $\begin{array}{l}\text { OTHER } \\
\mathrm{N}(8)\end{array}$ & $\begin{array}{l}\text { TOTAL } \\
\mathrm{N}(\%) \\
\end{array}$ \\
\hline White & $63(91.3)$ & $24(100)$ & $22(91.7)$ & $109(93.2)$ \\
\hline other & $6(8.7)$ & 0 & $2(8.3)$ & $8(6.8)$ \\
\hline$\overline{\text { TOTAL }}$ & $69(100)$ & $24(100)$ & $24(100)$ & $117(100)$ \\
\hline
\end{tabular}


Primary Income Source: A rather high proportion of the alcohol and drug subjects have self/family reported as their primary income source during all or part of the two-year study period. Just over half of the psýchosis group and $428^{\circ}$ of. the "other" group fall into this same category.

TABLE D3E: PRIMARY INCOME SOURCE AND PRIMARY DIAGNOSIS $\begin{array}{lllll}\text { CHARACTERISTIC: } & \text { PSYCHOSIS } & \text { A \& D } & \text { OTHER } & \text { TOTAL } \\ \text { PRIMARY INCOME } & \text { N }(z) & \text { N }(z) & N(z) & N(z)\end{array}$ SOURCE

\begin{tabular}{|l|c|c|r|c|}
\hline Self/Family & $43(51.2)$ & $18(72)$ & $11(42.3$ & $72(53.3)$ \\
\hline Welfare & $16(19)$ & $4(16)$ & $7(26.9$ & $27(20)$ \\
\hline Socteran Admin. & $1(1.2)$ & 0 & $1(3.8)$ & $2(1.5)$ \\
\hline Other security & $17(20.2)$ & $2(8)$ & $3(11.5$ & $22(16.3)$ \\
\hline Total & $7(8.3)$ & $1(4)$ & $4(15.4$ & $12(8.9)$ \\
\hline Income Source information was not obtained on 9 clients
\end{tabular}


Gross Family Income: The psychosis and "other" diagnostic subjects tend to be similar to each other on this variable. A larger proportion of the alcohol and drug subjects tend to fall into the higher income categories when compared to the other two groups.

TABLE D3F: GROSS FAMILY INCOME AND PRIMARY DIAGNOSIS $\begin{array}{lllll}\text { CHARACTERISTIC: } & \text { PSYCHOSIS } & \text { A \& D } & \text { OTHER } & \text { TOTAL } \\ \text { GROSS FAMIIY } & \mathbf{N}(z) & \mathbf{N}(z) & \mathbf{N}(z) & \mathbf{N}(z) \\ \text { INCOME } & & & & \end{array}$

\begin{tabular}{|l|c|c|c|c|}
\hline $\begin{array}{l}\text { Under } \$ 3,000 \\
\$ 3,000-\$ 5,999\end{array}$ & $28(54.9)$ & $3(50)$ & $7(58.3)$ & $38(55.1)$ \\
\hline $\begin{array}{l}\$ 6,000-\$ 8,999 \\
\vdots\end{array}$ & $7(13.7)$ & $1(16.7)$ & $3(25)$ & $13(18.8)$ \\
\hline $9,000+$ & $7(13.7)$ & $2(33.3)$ & $1(8.3)$ & $10(14.5)$ \\
\hline TOTAI & $51(100)$ & $6(100)$ & $12(100)$ & $69(100)$ \\
\hline MEDIAN & $\$ 2784.8$ & $\$ 4498.5$ & $\$ 2784.8$ & $\$ 2762$ \\
\hline Number of subjects whose Income is unknown $=48$ & \\
\hline
\end{tabular}


Residence: There does not seem to be any relationship between primary diagnosis and location of residence. 


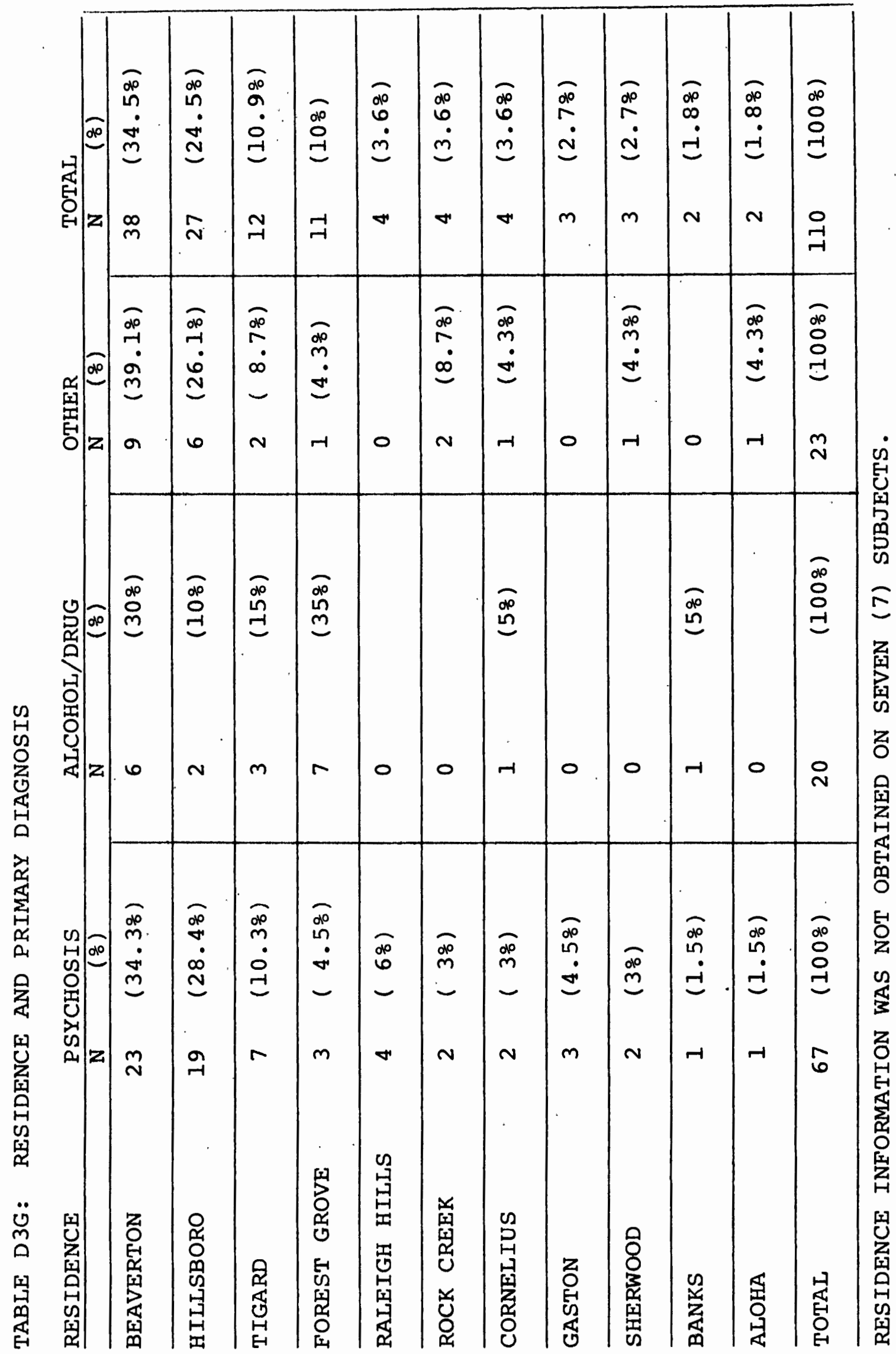


Section 4: The Relationship Between Selected Subject Characteristics and Hospital Commitment Type.

Age: Subjects who were court committed at some point during the study period tend to be younger (Median age = 30.9) than those who were not court committed (Median age $=36.6)$

THE RELATIONSHIP BETWEEN SELECTED SUBJECT CHARACTERISTICS AND COMMITMENT TYPE

TABLE D4A: AGE AND COMMITMENT TYPE CHARACTERISTIC: NOT COURT AGE COMMITTED COMMITTED

TOTAL N ( 8$)$ $\mathrm{N}(8) \quad \mathrm{N}(8)$

\begin{tabular}{|c|c|c|c|}
\hline $12-17$ Years & $1(1.2)$ & 0 & $1(.9)$ \\
\hline $18-44$ Years & $58(67.4)$ & $20(64.5)$ & $78(66.7)$ \\
\hline $65-64$ Years & $22(25.6)$ & $7(22.6)$ & $29(24.8)$ \\
\hline TOTAL & $5(5.8)$ & $4(12.9)$ & $9(7.7)$ \\
\hline MEDIAN AGE & 36.6 & $31(100)$ & $117(100)$ \\
\hline
\end{tabular}


Sex: Higher proportions of males tend to make up the court committed group than would be expected given the research population sex characteristics.

TABLE D4B: SEX AND COMMITMENT TYPE

\begin{tabular}{|c|c|c|c|}
\hline $\begin{array}{l}\text { CHARACTERISTIC: } \\
\text { SEX }\end{array}$ & $\begin{array}{l}\text { NOT COURT } \\
\text { COMMITTED } \\
\mathrm{N}(8) \\
\end{array}$ & $\begin{array}{l}\text { COURT } \\
\text { COMMITTED } \\
\mathrm{N}(8) \\
\end{array}$ & $\begin{array}{l}\text { TOTAL } \\
\mathrm{N}(8) \\
\end{array}$ \\
\hline Male & $43(50)$ & $18(58.1)$ & $61(52.1)$ \\
\hline Female & $43(50)$ & $13(41.9)$ & $56(47.9)$ \\
\hline TOTAL & $86(100)$ & $\overline{31(100)}$ & $117(100)$ \\
\hline
\end{tabular}

Marital Status: Court committed subjects tend to have a lower percentage of married and a higher percentage of divorced members than the comparison group.

TABLE D4C: MARITAL STATUS AND COMMITMENT TYPE

\begin{tabular}{l|c|c|c|}
$\begin{array}{l}\text { CHARACTERISTIC: } \\
\text { MARITAL STATUS }\end{array}$ & $\begin{array}{l}\text { NOT COURT } \\
\text { COMMITTED } \\
\mathrm{N}(8)\end{array}$ & $\begin{array}{l}\text { COURT } \\
\text { COMMITTED } \\
\mathrm{N}(8)\end{array}$ & $\begin{array}{l}\text { TOTAL } \\
\mathrm{N}(8)\end{array}$ \\
\hline Single & $27(31.4)$ & $10(32.3)$ & $37(31.6)$ \\
\hline Married & $30(34.9)$ & $6(19.4)$ & $36(30.8)$ \\
\hline Divorced & $20(23.3)$ & $11(35.5)$ & $31(26.5)$ \\
\hline Widowarated & $6(7)$ & $1(3.2)$ & $7(6)$ \\
\hline TOTAL & $3(3.5)$ & $3(9.7)$ & $6(5.1)$ \\
\hline
\end{tabular}


Race: The data indicates that non-whites may be over represented in the court committed group.

TABLE D4D: RACE AND COMMITMENT TYPE

\begin{tabular}{|c|c|c|c|}
\hline $\begin{array}{l}\text { CHARACTERISTIC: } \\
\text { RACE }\end{array}$ & $\begin{array}{l}\text { NOT COURT } \\
\text { COMMITTED } \\
\mathrm{N}(\mathrm{8})\end{array}$ & $\begin{array}{l}\text { COURT } \\
\text { COMMITTED } \\
\mathrm{N}(\mathrm{z})\end{array}$ & $\begin{array}{l}\text { TOTAL } \\
\text { N (8) } \\
\end{array}$ \\
\hline White & $82(95.3)$ & $27(87.1)$ & $109(93.2)$ \\
\hline other & $4(4.7)$ & $4(12.9)$ & $8(6.8)$ \\
\hline TOTAL & $86(100)$ & $31(100)$ & $117(100)$ \\
\hline
\end{tabular}


Primary Income Source: The court committed group tends to have a:higher proportion of subjects reporting as their primary income source self/family and lower proportion indicating welfare than would be expected given the study population characteristics on this variable.

TABLE D4E: PRIMARY INCOME SOURCE

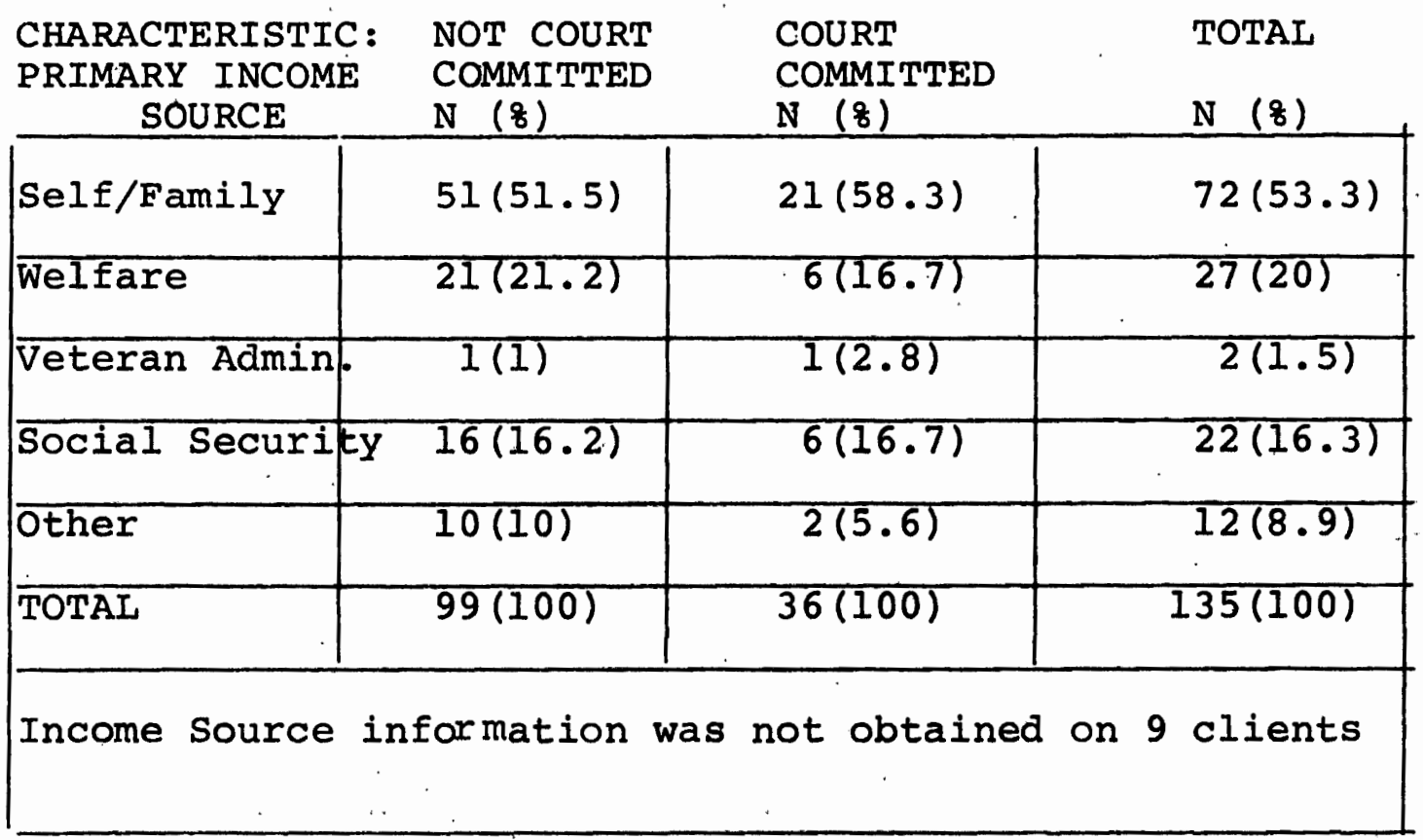


Gross Family Income: There appears to be a relationship between commitment status and income level. Generally, court committed subjects tend to have higher gross incomes than non-court committed subjects.

TABIE D4F: GROSS FAMILY INCOME AND COMMITMENT STATUS

\begin{tabular}{|c|c|c|c|c|}
\hline $\begin{array}{l}\text { GROSS FAMILY } \\
\text { INCOME }\end{array}$ & $\begin{array}{l}\text { NOT COURT } \\
\text { COMMITTED }\end{array}$ & $\begin{array}{l}\text { COURT } \\
\text { COMMITTED }\end{array}$ & \multicolumn{2}{|c|}{ TOTAL } \\
\hline & $\mathrm{N} \quad(8)$ & $\mathrm{N} \quad(8)$ & $\mathrm{N}$ & $(\%)$ \\
\hline Under $\$ 3,000$ & $26 \quad\left(59.18^{\prime}\right)$ & $12(488)$ & 38 & $(55.18)$ \\
\hline$\$ 3,000-\$ 5,999$ & $7 \quad(15.98)$ & $6 \quad(248)$ & 13 & $(18.88)$ \\
\hline$\$ 6,000-\$ 8,999$ & $5 \quad(11.48)$ & $3 \quad(128)$ & 8 & $(11.68)$ \\
\hline$\$ 9,000$ plus & $6 \quad(13.68)$ & $4 \quad(168)$ & 10 & $(14.58)$ \\
\hline TOTAL & $44 \quad(1008)$ & $25 \quad(1008)$ & 69 & $(100 \%)$ \\
\hline MEDIAN & $\$ 2,595$ & $\$ 3,499$ & $\$ 2$ & 62 \\
\hline
\end{tabular}


Residence: The item of most interest is the figure that 40.68 of the court committed subjects (compared to 18.58 of the non-court committed subjects) lived in Hillsboro. This item is of interest primarily because Hillsboro is also where the County's mental health program responsible for investigating commitment petitions and the monitoring of court committed individuals is located. This finding could suggest that chronically mentally ill residents of Hillsboro tend to be court committed at higher rates than other county residents. However, it is quite possible that residents could have been established after being court committed. The available data does not allow for specific time comparisons. 
TABLE D4G: RESIDENCE AND COMMITMENT STATUS

\begin{tabular}{|c|c|c|c|c|c|c|}
\hline \multirow{3}{*}{ RESIDENCE } & \multicolumn{2}{|c|}{$\begin{array}{l}\text { NOT COURT } \\
\text { COMMITTED }\end{array}$} & \multicolumn{2}{|c|}{$\begin{array}{l}\text { COURT } \\
\text { COMMITTED }\end{array}$} & \multicolumn{2}{|c|}{ TOTAL } \\
\hline & $\mathrm{N}$ & $\left(\frac{8}{8}\right)$ & $\mathrm{N}$ & $(8)$ & $\mathbf{N}$ & $\left(\frac{8}{3}\right)$ \\
\hline & 30 & $(378)$ & 8 & $(27.68)$ & 38 & $(34.5 \%)$ \\
\hline HILLSBORO & 15 & $(18.58)$ & 12 & $(41.48)$ & 27 & $(24.58)$ \\
\hline TIGARD & 11 & $(13.68)$ & 1 & $(3.48)$ & 12 & $(10.98)$ \\
\hline FOREST GROVE & 9 & $(11.18)$ & 2 & $(6.98)$ & 11 & $(10 \%)$ \\
\hline RALEIGH HILLS & 1 & $(1.28)$ & 3 & $(10.38)$ & 4 & $(3.6 \%)$ \\
\hline ROCK CREEK & 3 & $(3.78)$ & 1 & $(3.48)$ & 4 & $(3.68)$ \\
\hline CORNELIUS & 4 & $(4.98)$ & 0 & & 4 & $(3.68)$ \\
\hline GASTON & 1 & $(1.28)$ & 2 & $(6.98)$ & 3 & $(2.78)$ \\
\hline SHERWOOD & 3 & $(3.78)$ & 0 & & 3 & $(2.78)$ \\
\hline BANKS & 2 & $(2.58)$ & 0 & & 2 & $(1.88)$ \\
\hline ALOHA & 2 & $(2.58)$ & 0 & & 2 & $(1.88)$ \\
\hline TOTAL & 81 & $(1008)$ & 29 & $(1008)$ & 110 & $(100 \%)$ \\
\hline
\end{tabular}


Primary Diagnosis: All but five of the court committed subjects are diagnosed as psychotic. Half of the non-court committed subjects fall into this category.

TABLE D4H: PRIMARY DIAGNOSIS AND COMMITMENT TYPE CHARACTERISTIC PRIMARY DIAGNOSIS NOT COURT COMMITTED $\mathrm{N} \quad(\mathrm{z})$ COURT COMMITTED TOTAL

\begin{tabular}{|lll|ll|l|l|}
\hline & N & $(8)$ & N & $(8)$ & N & $(8)$ \\
\hline Psychosis & 43 & $(50)$ & 26 & $(83.9)$ & 69 \\
\hline A \& D & 21 & $(24.4)$ & 3 & $(9.7)$ & 24 & $\frac{(59)}{(20.5)}$ \\
\hline Other & 22 & $(25.6)$ & 2 & $(6.5)$ & 24 & $\frac{(20.5)}{(100)}$ \\
\hline TOTAL & 86 & $(100)$ & 31 & $(100)$ & 117 \\
\hline
\end{tabular}




\section{Part Three - The Relationship Between the Utilization of Mental Health Sub- contract Agencies and Selected Variables.}

The previous parts of this chapter have been concerned with a descriptive analysis of the chronic aftercare population. In the following sections, the focus will shift to an examination of services utilization data pertaining to Washington County's Mental Health Subcontract Agencies. Specifically, we will examine the relationship between the utilization of individual agencies and selected variables.

Section 1: Agency Utilization and Duration of Treatment.

There does tend to be a relationship between the agency providing treatment and the length of time the subject remains in treatment. Comparatively, longer treatment stays are associated with Tualatin Valley Mental Health Center and Tualatin Valley Workshop. The data shows that 54.58 of the subjects who were clients of Tualatin Valley Mental Health Center and 28.68 of those seen at Tualatin Valley Workshop were in treatment longer than 180 days. Only one subject served by the other three agencies fell into this category. 


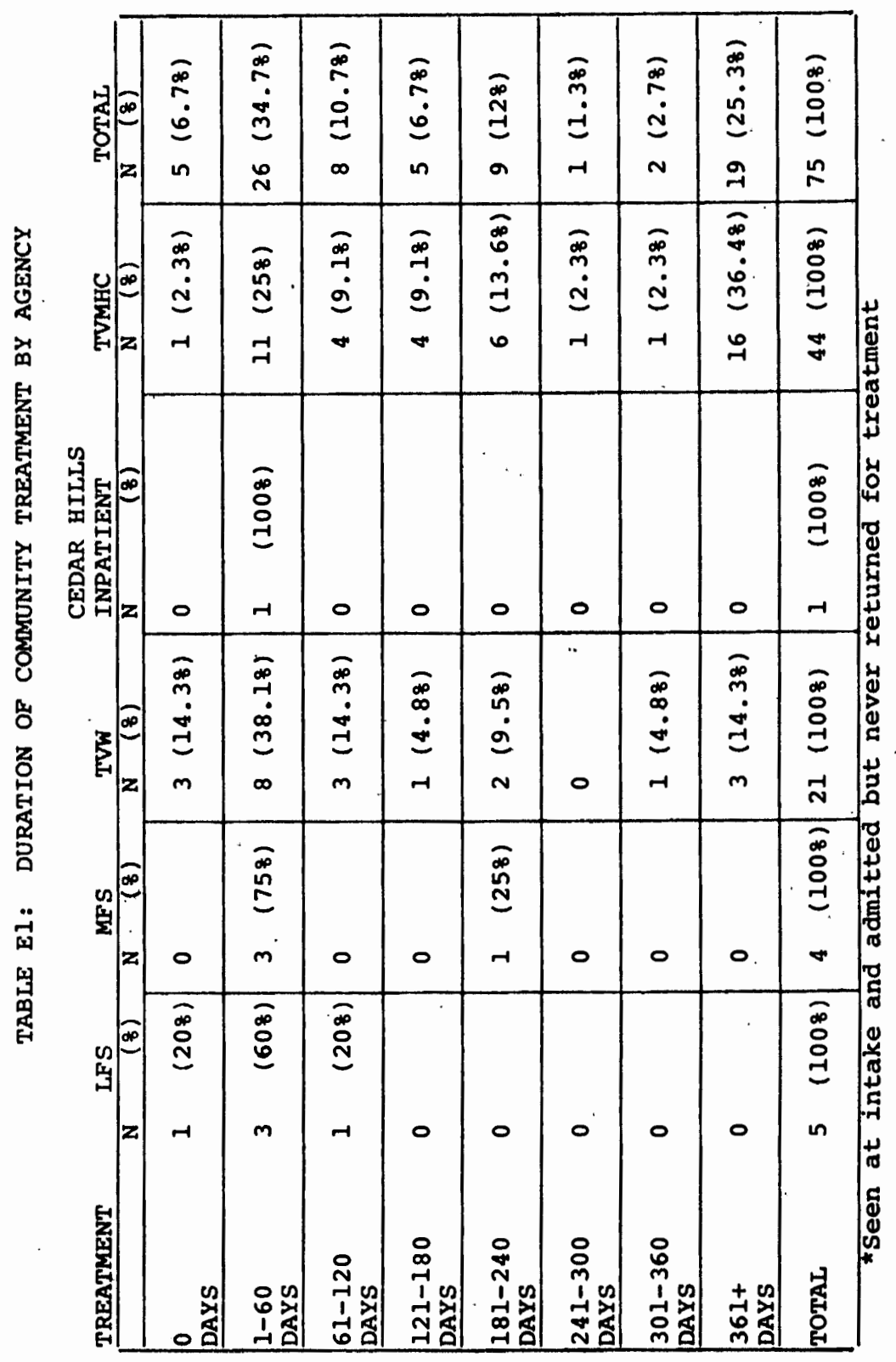


Section 2: Agency Utilization and gross Family Income.

More than half of the Tualatin Valley Mental Health Center and/or Tualatin Valley Workshop clients have family incomes under $\$ 3,000$. The clientele of the other three agencies tend to be more affluent, as indicated by the fact that 608 of the client contacts with these service providers involves subjects with incomes in excess of $\$ 6,000$. 


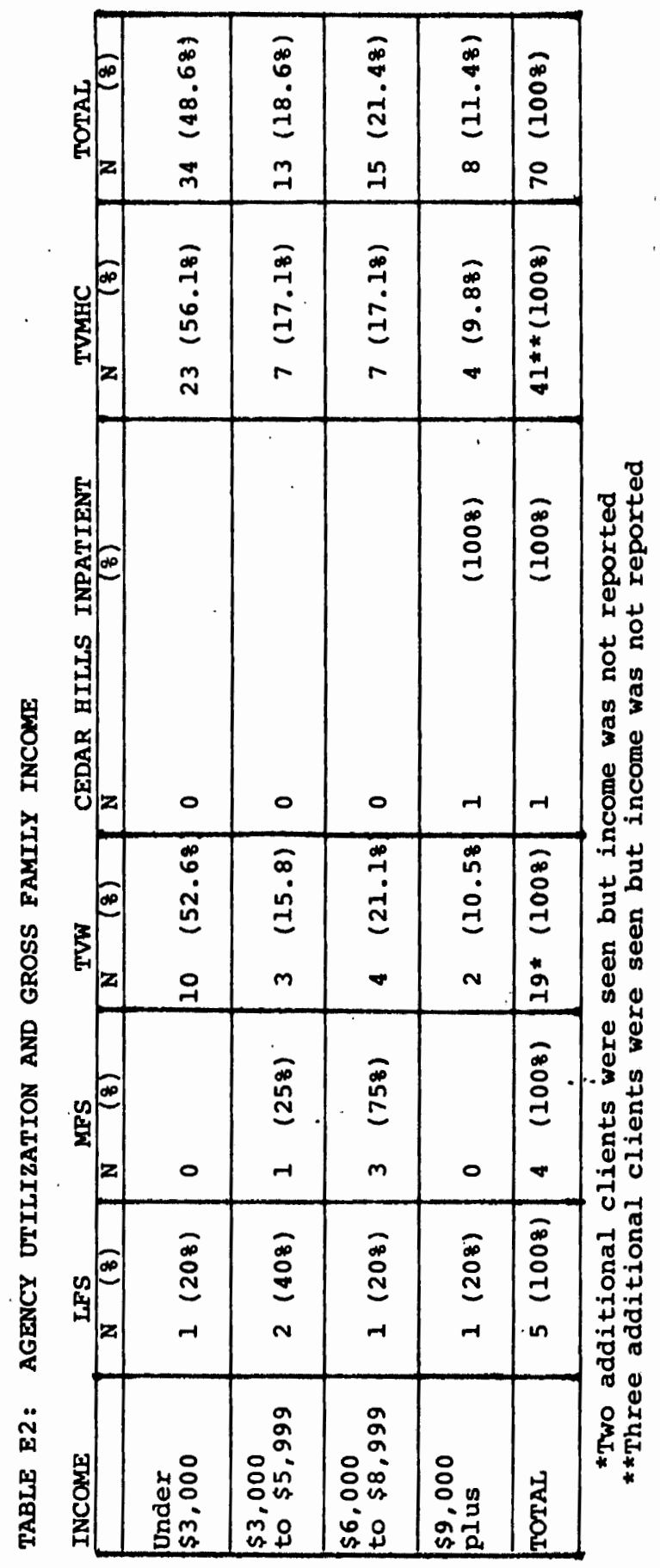


Section 3: Agency Utilization and Location of Residence

The reader will recall that almost all of the research population tends to be located within the Tualatin Valley, an area which occupies the southwest portion of Washington County. Even though the chronic aftercare subjects tend to be concentrated within this one area, we see some variance in terms of where the five subcontract agencies draw their clientele. Tualatin Valley Mental Health Center and Tualatin Valley Workshop's aftercare clientele come from all portions of the valley, and even a few locations outside the valley. Subjects served by the other three agencies come primarily from Beaverton or Hillsboro. 


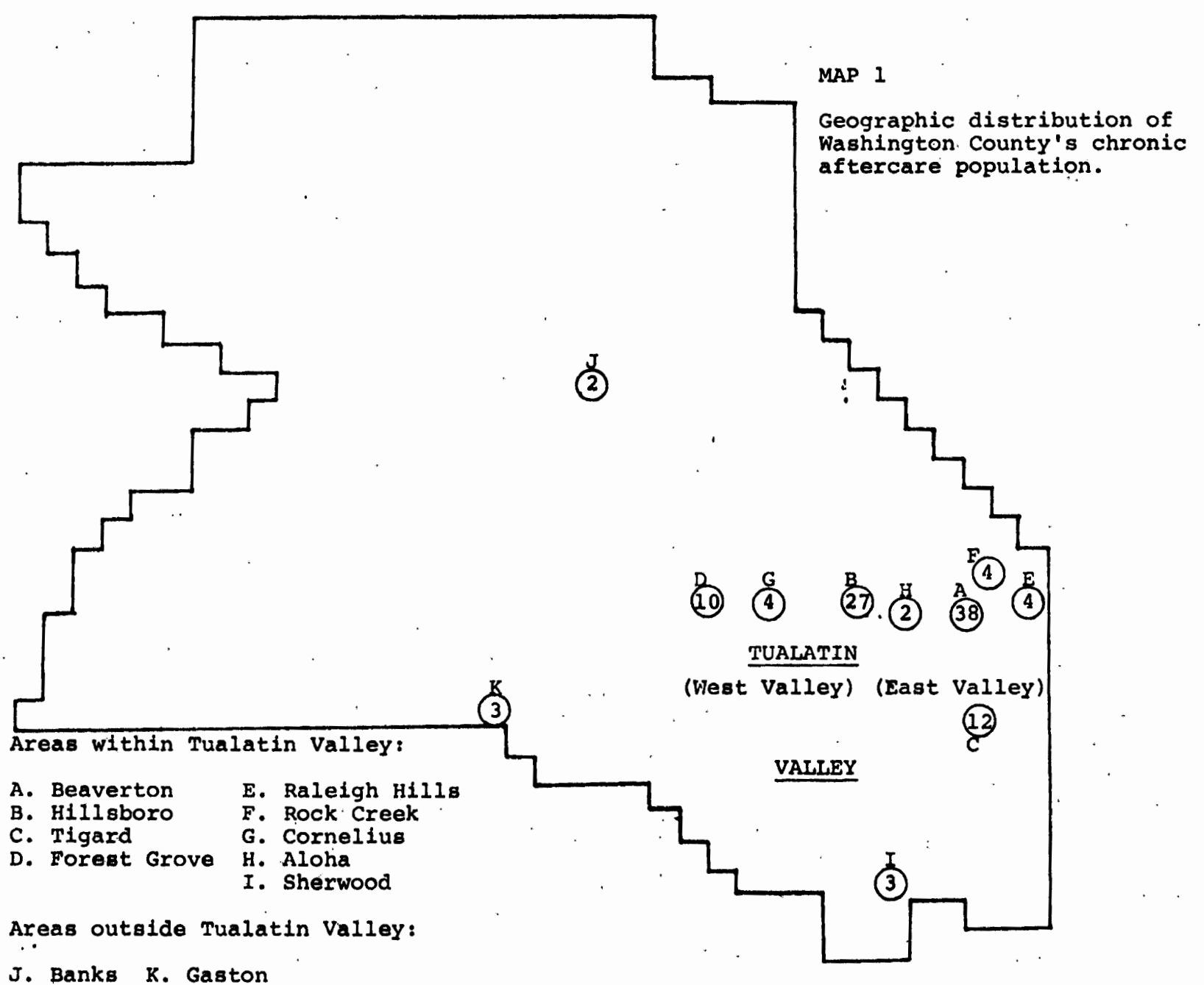




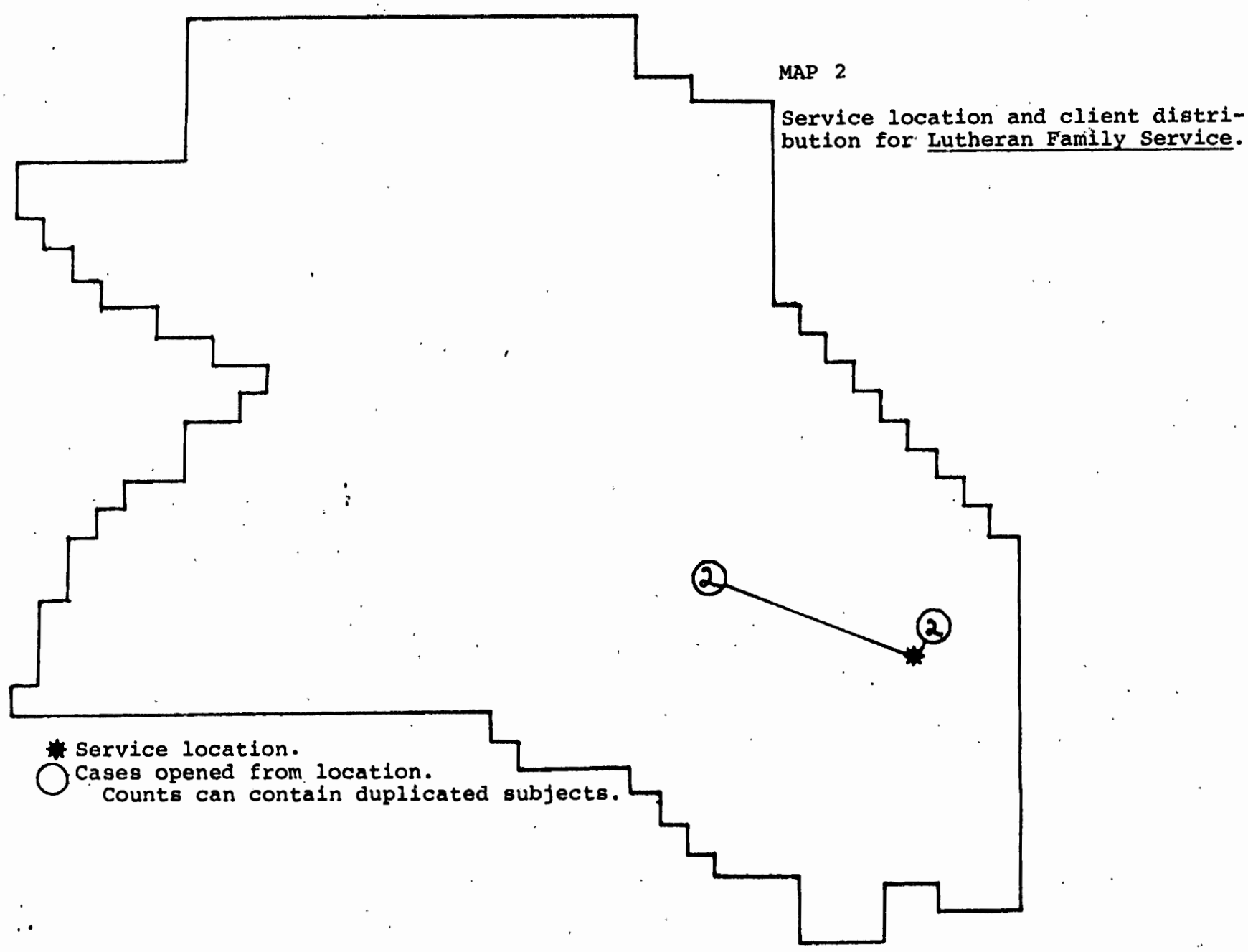




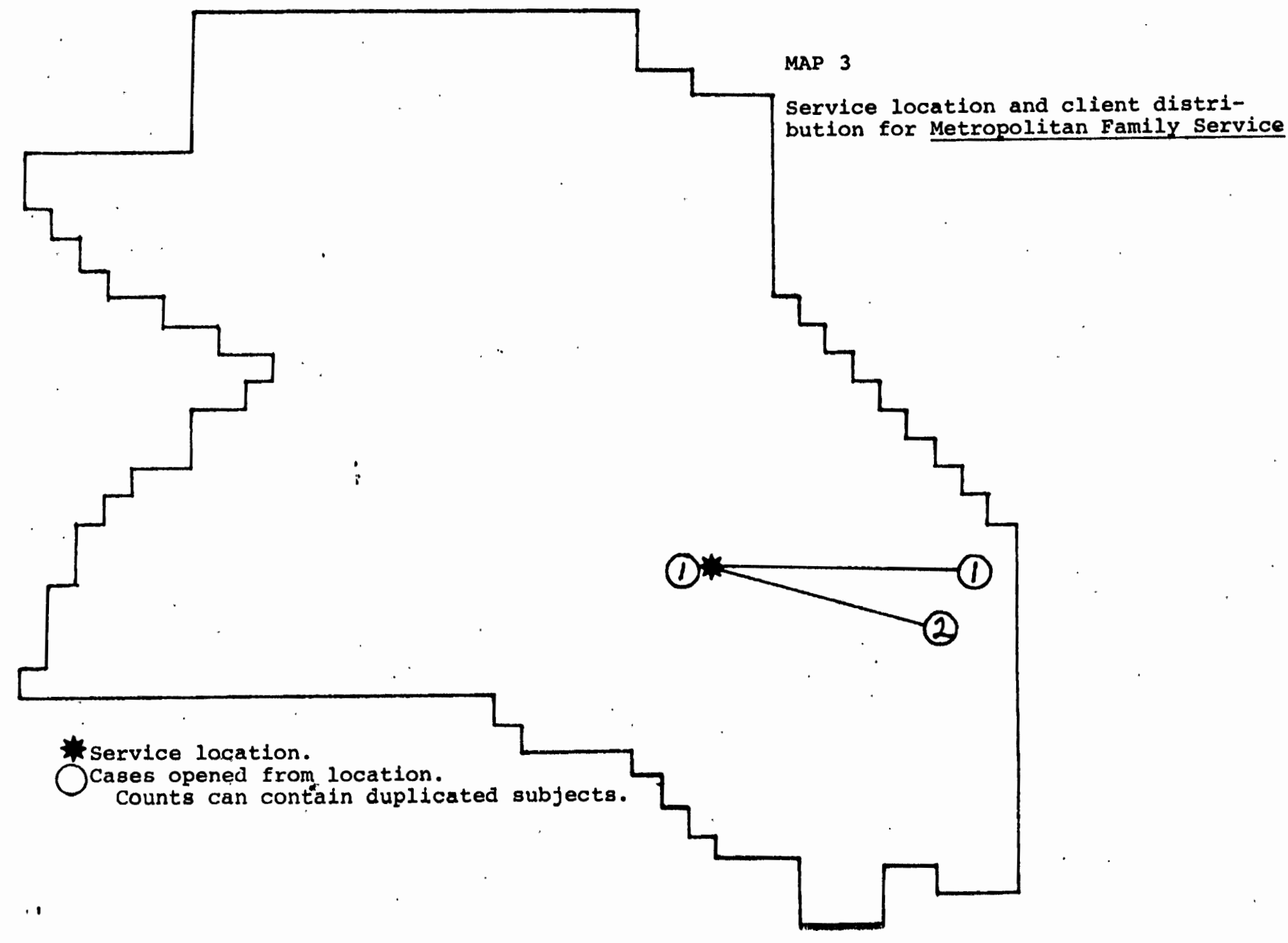




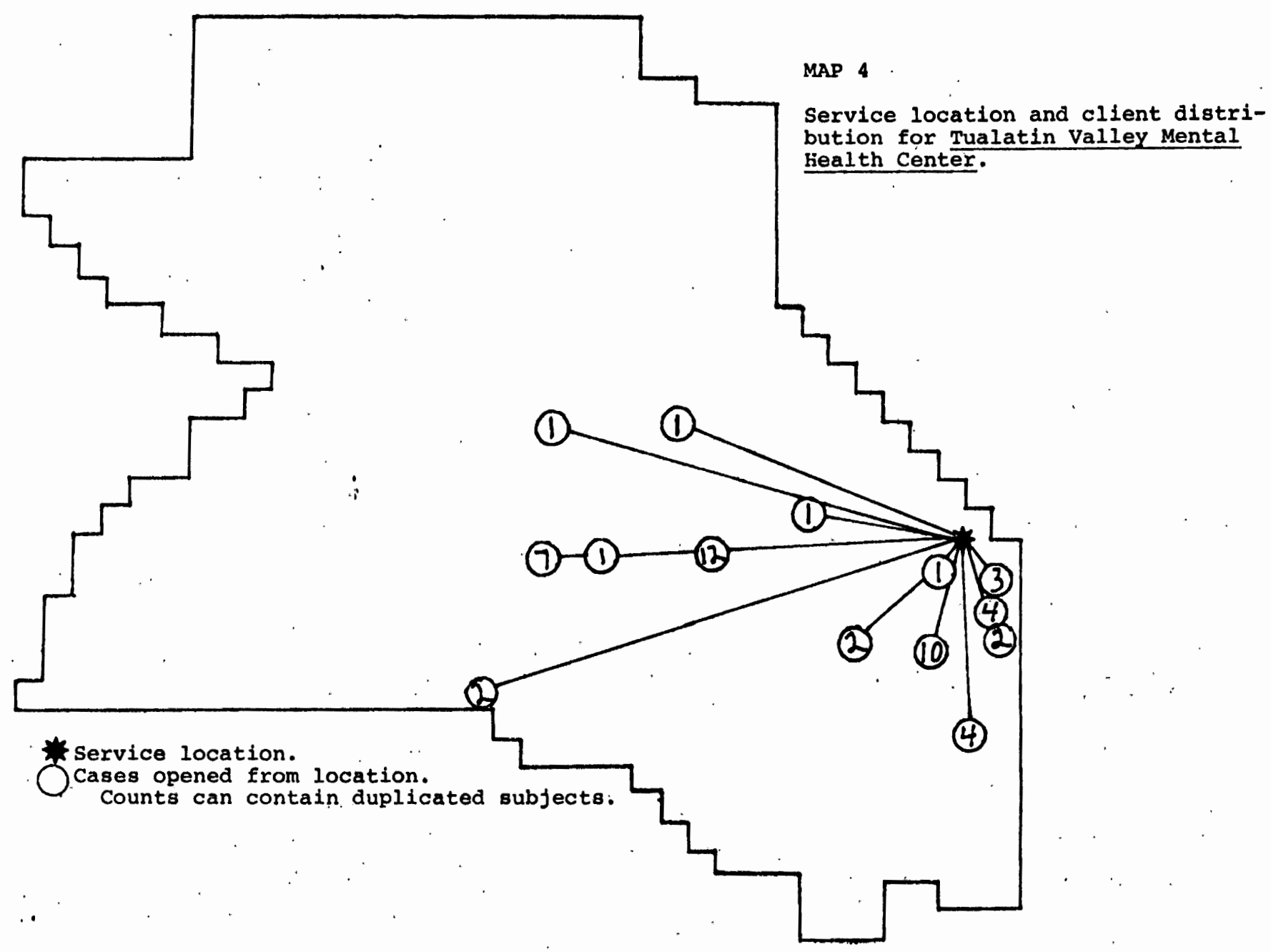




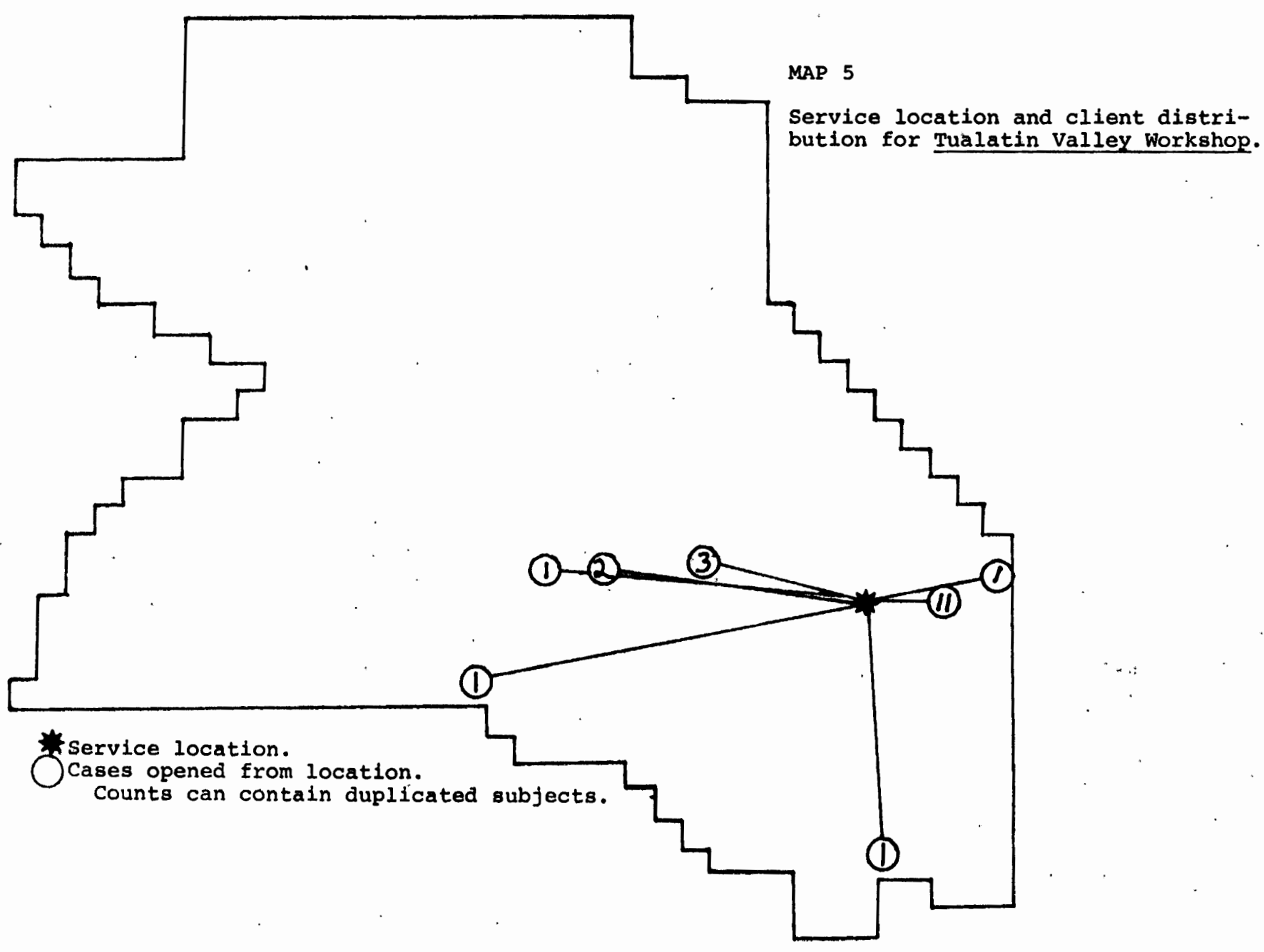


Section 4: Agency Utilization and Hospital Admissions.

All of the agencies except for Lutheran Family

Services had approximately 758 of their subject contacts with individuals who incurred two or more Dammasch State Hospital admissions during the study period. Most of the subjects served by Lutheran Family Services had only one admission. Tualatin Valley Workshop had the highest proportion (42.98) of subjects with three or more admissions, while tualatin Valley Mental Health Center was second with 36.48 of its subjects contacts being individuals in this category. Metropolitan Family Service was the only other agency that served a member of the research population with three or more admissions. 


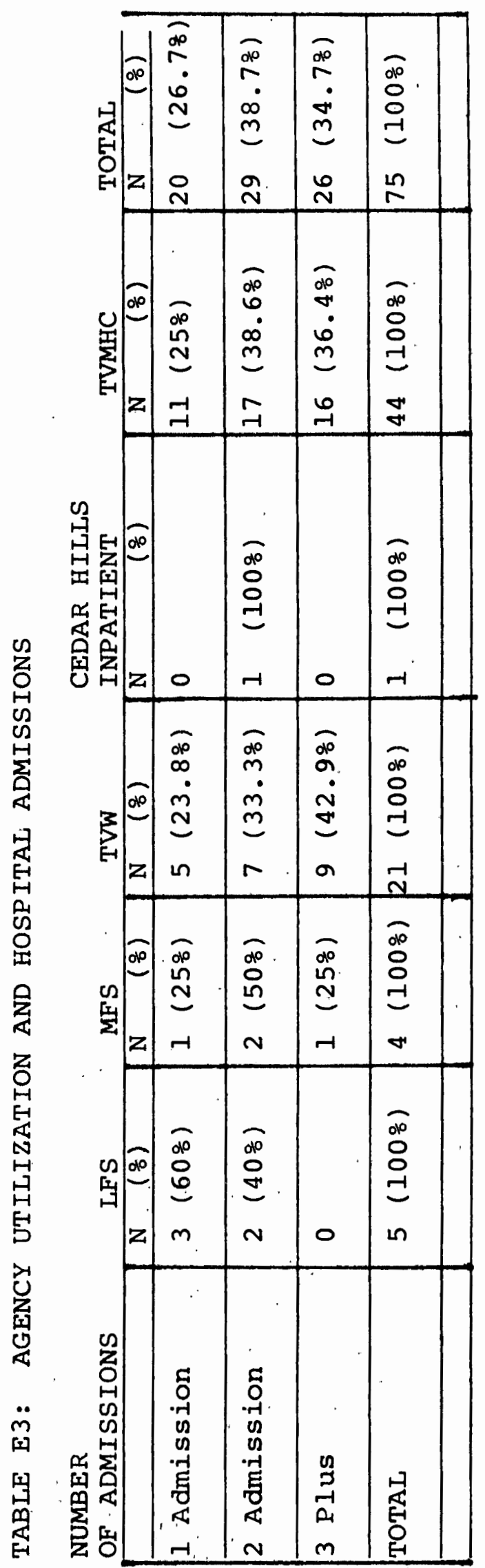


Section 5: Agency Utilization and Total Days in the Hospital. Approximately $60 \%$ of the subjects treated by Tualatin Valley Workshop and a little less than half of those seen at Tualatin Valley Mental Health Center had a total of $90+$ hospital days accumulated during the two year period of the study. Of the remaining three service providers, only Metropolitan Family Service treated a subject with more than 90 days in the hospital. 


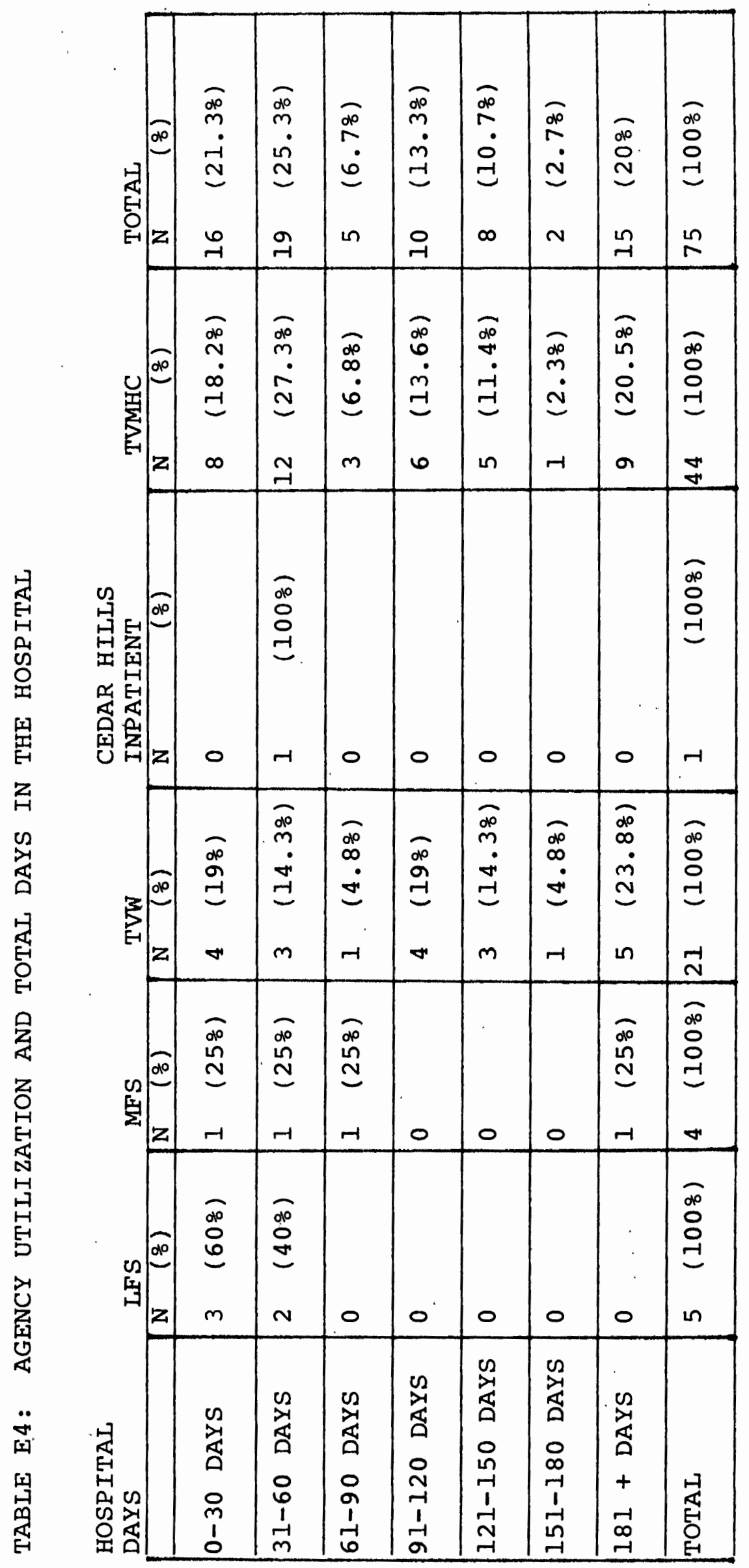


Section 6: Agency Utilization and Primary Diagnosis.

Approximately 808 of both Tualatin Valley Workshop's and Tualatin Valley Mental Health Center's subject contacts were with individuals diagnosed as psychotic. Three of the four subjects seen by Metropolitan Family Service were so categorized, while the majority of individuals seen at the two remaining agencies have alcohol and drug or "other" diagnosis. 


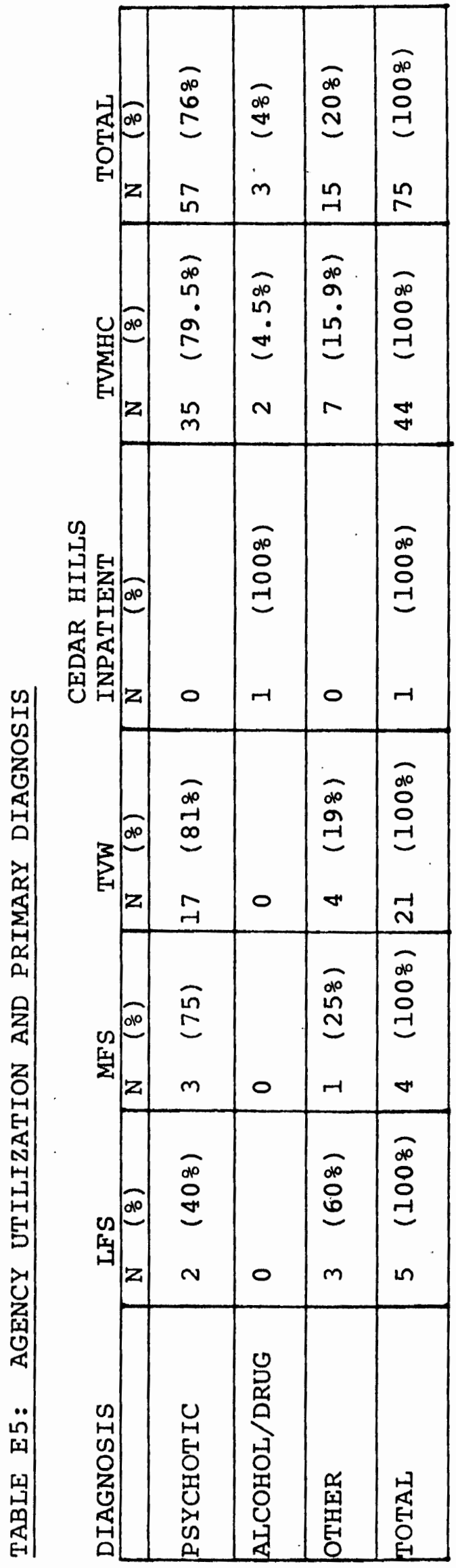


Section 7: Agency Utilization and Hospital Commitment Type.

One-fourth of the subjects served by Tualatin Valley Mental Health Center and the three lesser utilized subcontractors were subjects who had been court committed at some point during the study period.' Thirty-eight percent (388) of Tualatin Valley Workshop's clients fall into this category. 


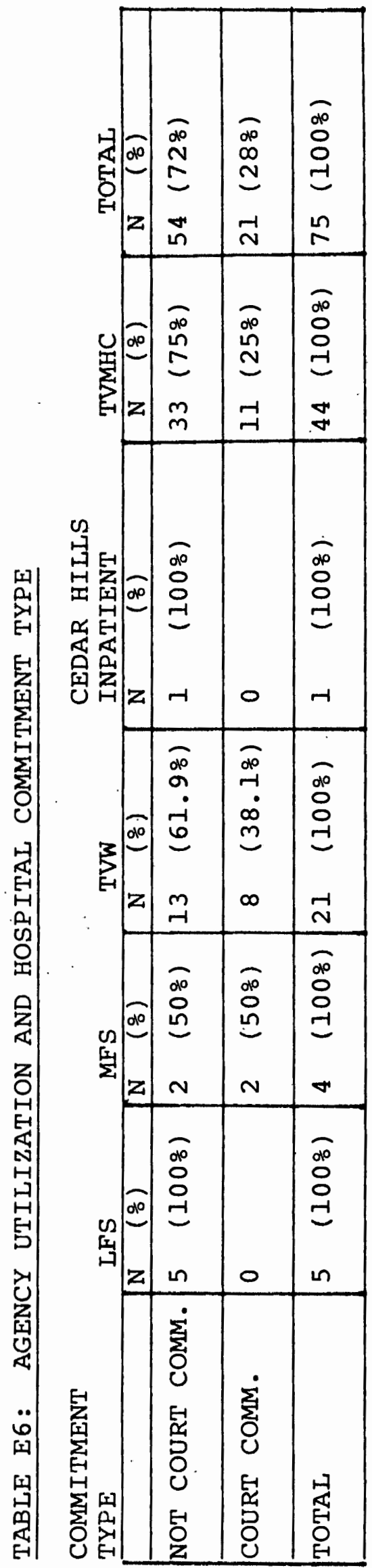


Section 8: Agency Utilization and Acknowledgement of Treatment Termination.

At termination of treatment, Metropolitan Family

Service and Tualatin Valley Workshop were the only agencies who tended to put in the client case files some indication of the nature of termination. 


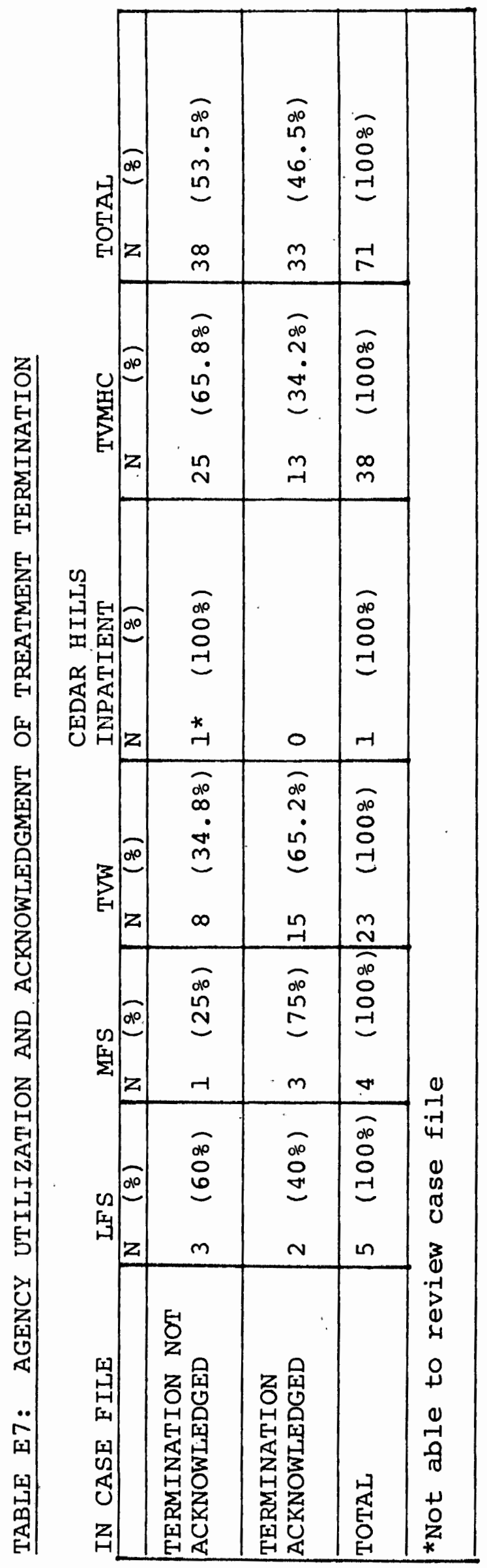




\section{Part Four - The Relationship Between \\ The Utilization of Services Coordination And Selected Variables.}

In Part Three, we examined the data in relation to subcontract agency utilization. In the following sections we will take a look at the utilization of services coordination and how it relates to a number of variables.

Section 1: Services Coordination and the Utilization of Subcontract Agencies.

The data shows that 56.18 of the subjects who utilized services coordination obtained treatment services through a subcontract agency. This compares to a 41.78 agency utilization figure for those individuals who were not services coordination clients. In all, 82 (70.1\%) of the 117 research subjects received some kind of aftercare service (services coordination and/or subcontract agency treatment). 


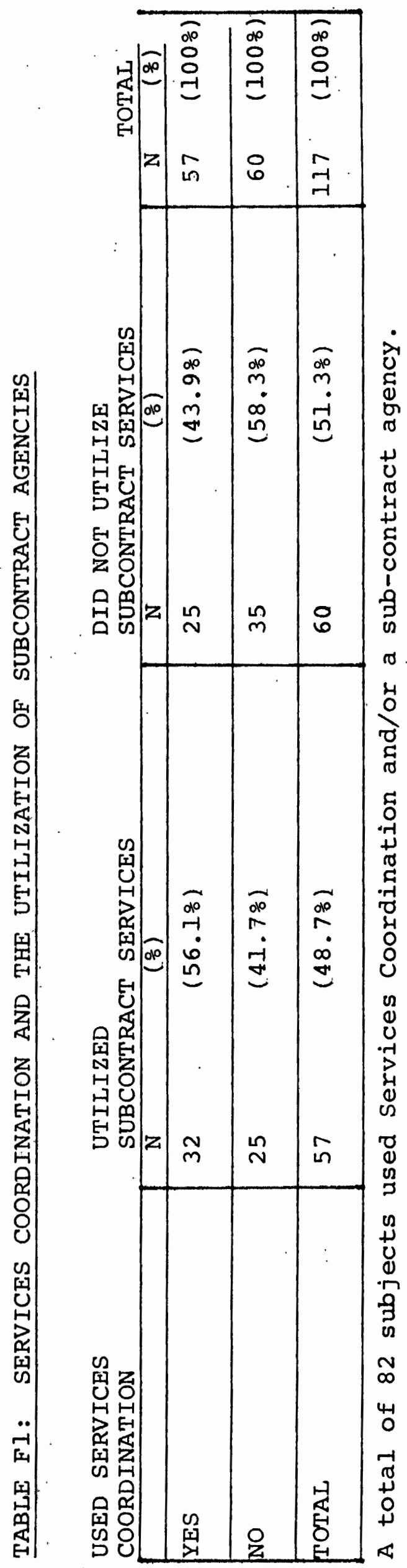


Section 2: Services Coordination and Total Days in Community Treatment.

The data shows that of the 32 subjects who utilized services coordination and were treated by a subcontract agency, 19 (59.4\%) had over 180 total days of community treatment, while only 448 of the subjects who were not services coordination clients (but received subcontract mental health services) fell into this category. Additionally, compared to the rest of the population, service coordination clients who were not court committed tended to have consistently longer stays in treatment than the other segments of the study population. 


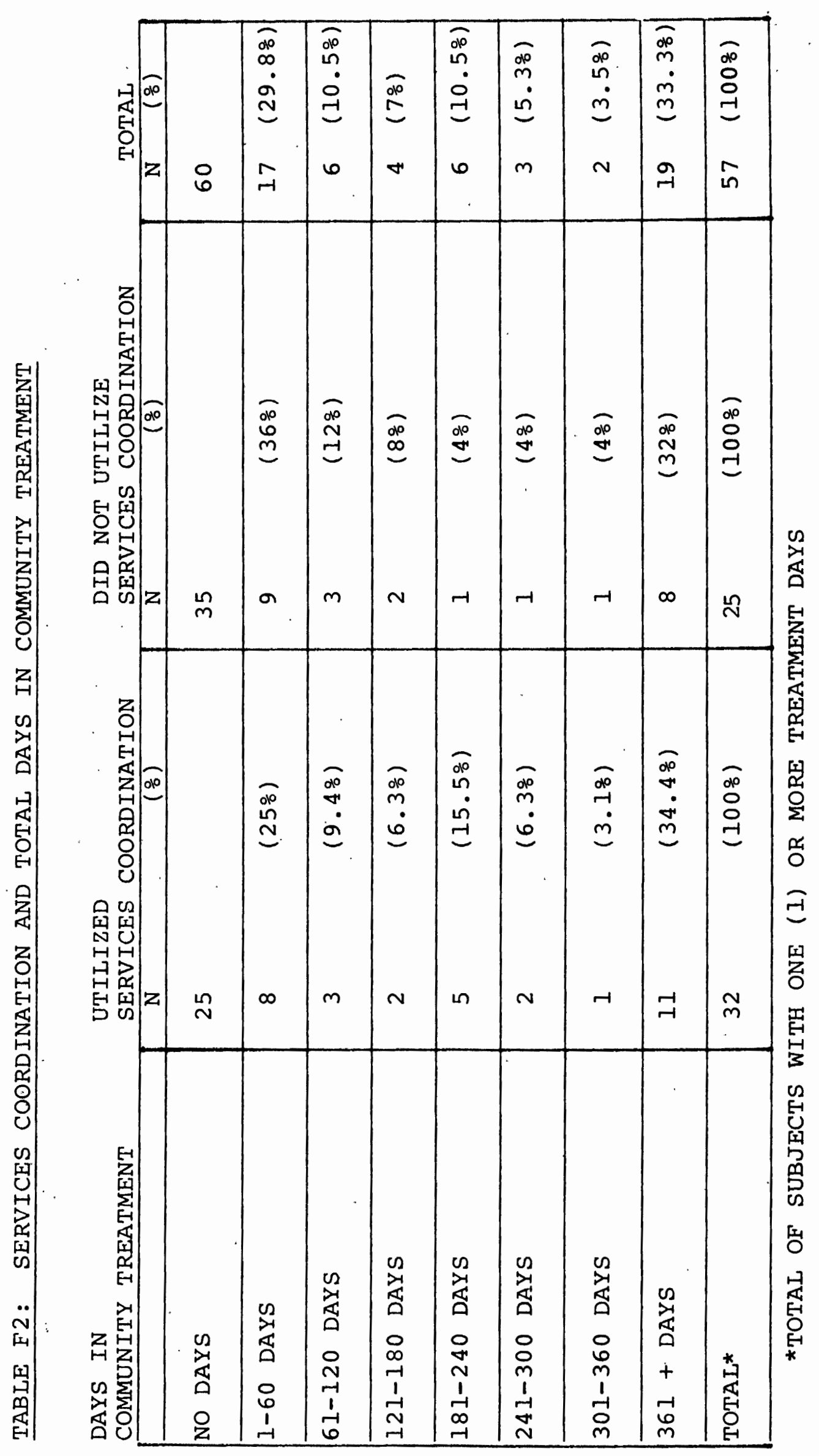


Section 3: Services Coordination and Acknowledgement of Treatment Termination.

There appears to be no relationship between the utilization of services coordination and whether a subject's termination is acknowledged in the agency case file. 


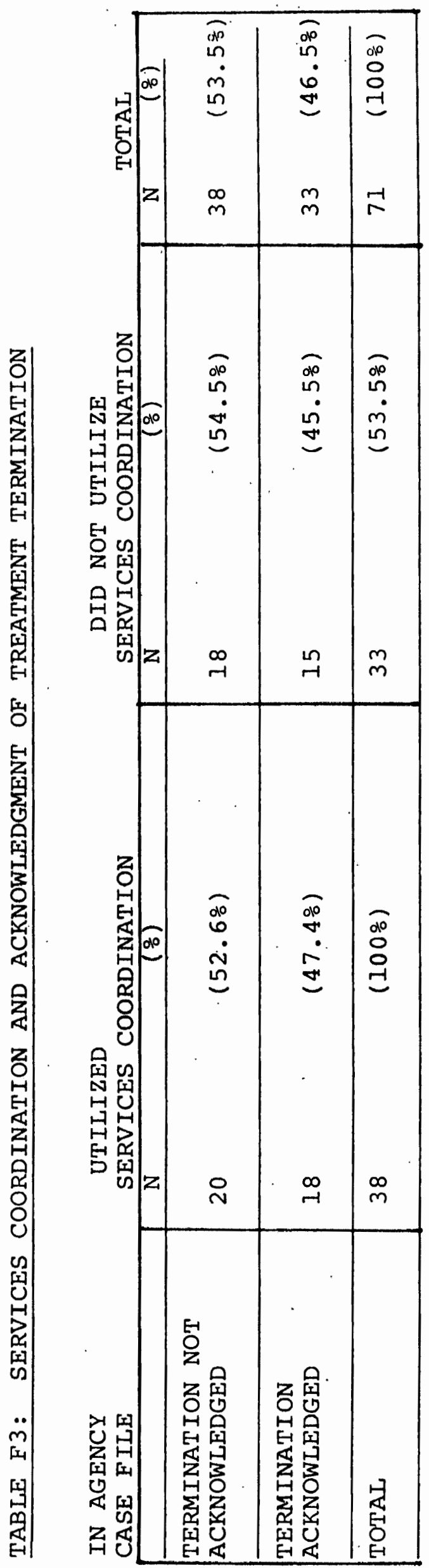


Part Five - The Chronological Relationship Between The Utilization of Aftercare Services And Admission to The State Hospital.

In the following two sections, the data will be examined to determine the relationship between the utilization of aftercare services and readmission to the hospital. In section one, the number of hospital admissions which occur while in treatment at a subcontract agency is identified. In section two, we will look at the period of time after hospital discharge to determine the extent to which services are utilized and the relationship between service utilization and rates of readmission to the hospital.

Section 1: Proportion of Subjects in Treatment (Subcontract Services) Just Prior to Hospitalization.

Slightly more than 178 of the Dammasch Hospital admissions incurred by this population (during the study period) occurred while the admittee was a subcontract agency client. 6

${ }^{6}$ Subjects who were agency clients at or within one week of hospital admission were included in this category. 


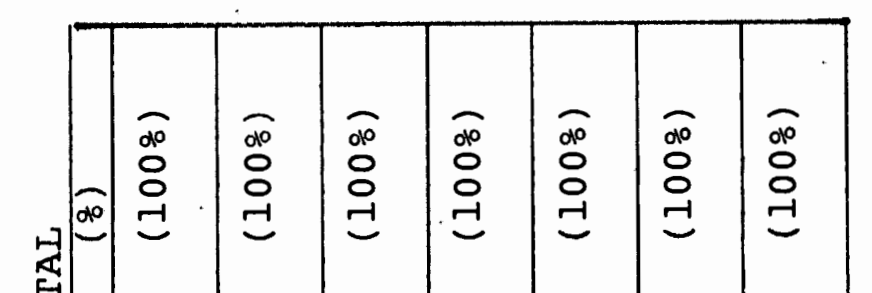

¿̇

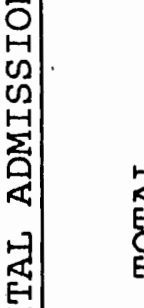

On

$z$

$\stackrel{+}{\sim}$

$\infty \operatorname{m}_{m} \underset{-1}{0} N$

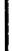

은

A

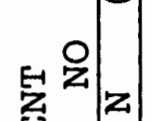

$\exists$

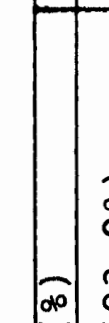

م)

\begin{tabular}{|l|l} 
& \\
\hline & \\
\hline & \\
$\dot{N}$ & \\
$\dot{\infty}$ & \\
\hline
\end{tabular}

\begin{tabular}{ll|l|l|l} 
& & & & \\
\hline & &
\end{tabular}

$\stackrel{\infty}{\sim}$

욜

₹.

नr

굥

4

노용

อ ญ

ชु

$+$

嵌 ธิ์

我.

+ 告

常

n

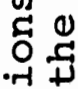

os

은

है

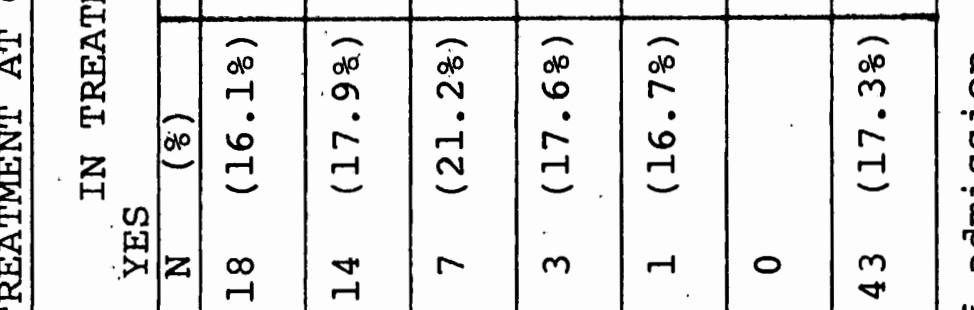

c 00

तु

近

-7 욤

- $\rightarrow$

ชृ 
Section 2: Service Utilization Patterns Following Hospital Discharge and Hospital Recidivism.

In examining the relationship between the utilization of aftercare services and readmission to the state hospital, the unit of analysis (called a community stay period) is the period of time between hospital release and either readmission (recidivism) to the hospital or the end of the study period (non-recidivism), whichever comes first. In that there was a range of one to six hospital admissions during the study time frame, there was also a possible range of one to six community stay periods. ${ }^{7}$ Naturally, each successive community stay period will contain fewer members since only those subjects who recidivated during the previous period are eligible to become members of the next community stay period. An examination of each of the community stay periods was carried out to determine in what way various patterns of aftercare services utilization relate to recidivism. In most of the analyses that follow the recidivism (hospital return) rates discussed will be an average rate for all six community stay periods. This is being done to simplify analyses and also because, in most cases, individual period rates tend to differ very little from the

${ }^{7}$ If release from the last hospitalization occurred after or within one month of the end of the study period (July 1, 1978), then there was considered to be no community stay period for that admission. Thus, some subjects had one less community stay period than admissions. 
average rate.

TABLE G2: UTILIZATION OF AFTERCARE SERVICES DURING COMMUNITY STAY PERIODS

\begin{tabular}{|c|c|c|c|c|c|c|}
\hline $\begin{array}{l}\text { C.S.P.* } \\
\text { FOLLOWING }\end{array}$ & & AFTERCARE & SER & $\begin{array}{r}\text { CES } \\
\text { NO } \\
\end{array}$ & \multicolumn{2}{|c|}{ TOTAL } \\
\hline & $N$ & $78)$ & $\bar{N}$ & $(8)$ & $\mathrm{N}$ & $(8)$ \\
\hline lst ADM. & 51 & $(45.58)$ & 61 & $(54.58)$ & 112 & $(1008)$ \\
\hline 2nd ADM. & 32 & $(46.48)$ & 37 & $(53.68)$ & 69 & (1008) \\
\hline 3rd ADM. & 13 & $(44.88)$ & 16 & $(55.28)$ & 29 & $(1008)$ \\
\hline 4th ADM. & 4 & $(30.88)$ & 9 & $(69.28)$ & 13 & $(1008)$ \\
\hline 5th ADM. & 1 & $(258)$ & 3 & $(758)$ & 4 & $(1008)$ \\
\hline 6th ADM. & 0 & & & $(1008)$ & 1 & $(1008)$ \\
\hline TOTAL & 101 & $(44.38)$ & 127 & $(55.78)$ & 228 & $(1008)$ \\
\hline
\end{tabular}

*Community stay Period

Following discharge from the hospital, an average of 44.38 of the subjects utilized aftercare (coordination and/ or subcontract) services during their respective community stay periods (see Table G2) . Interestingly enough, the non-utilization of aftercare services tends to be associated with a lower overall hospital return rate than that of the utilization category (see Table G3).. This relationship holds true for the first, second, and third hospital stay periods. Following the fourth admission, the trend reverses and more favorable (comparative) rates 
were typical of the subjects who used aftercare services. 


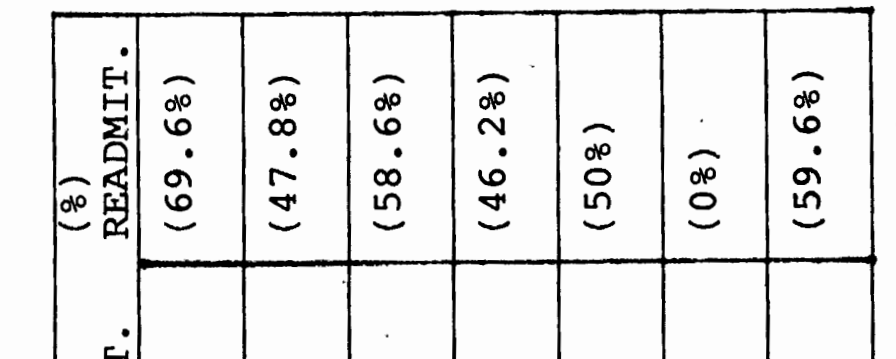

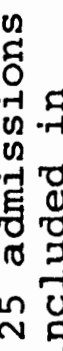
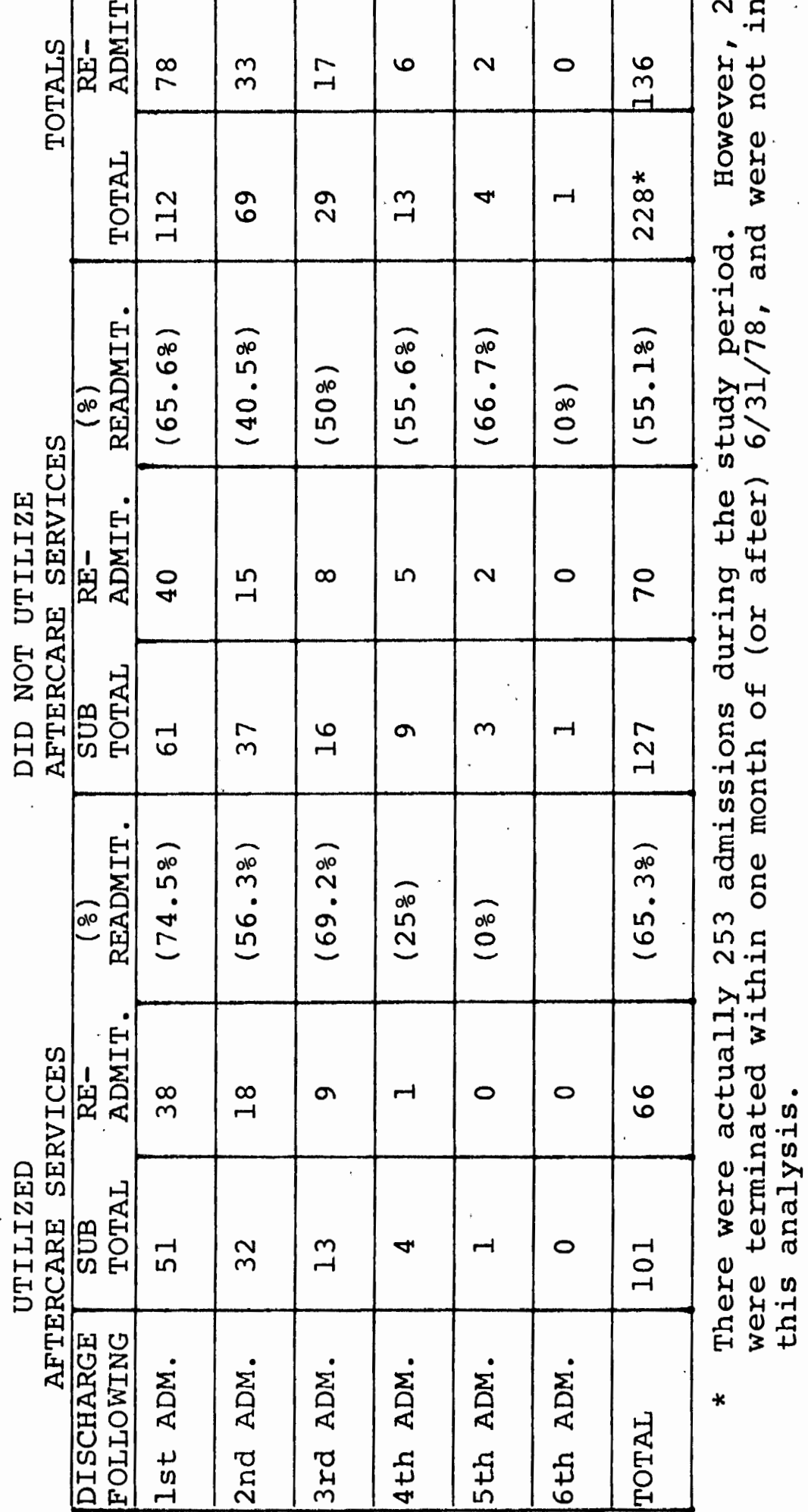
Looking at the data more closely, we find on Table G3A that subjects who were treated by a subcontract agency during their community stay periods consistently had lower hospital return rates than subjects who did not receive these services. Table G4 shows that the reverse is true for services coordination utilization. In other words, individuals who used services coordination tended to return to the hospital at higher rates than subjects who did not receive this service during a community stay period. 


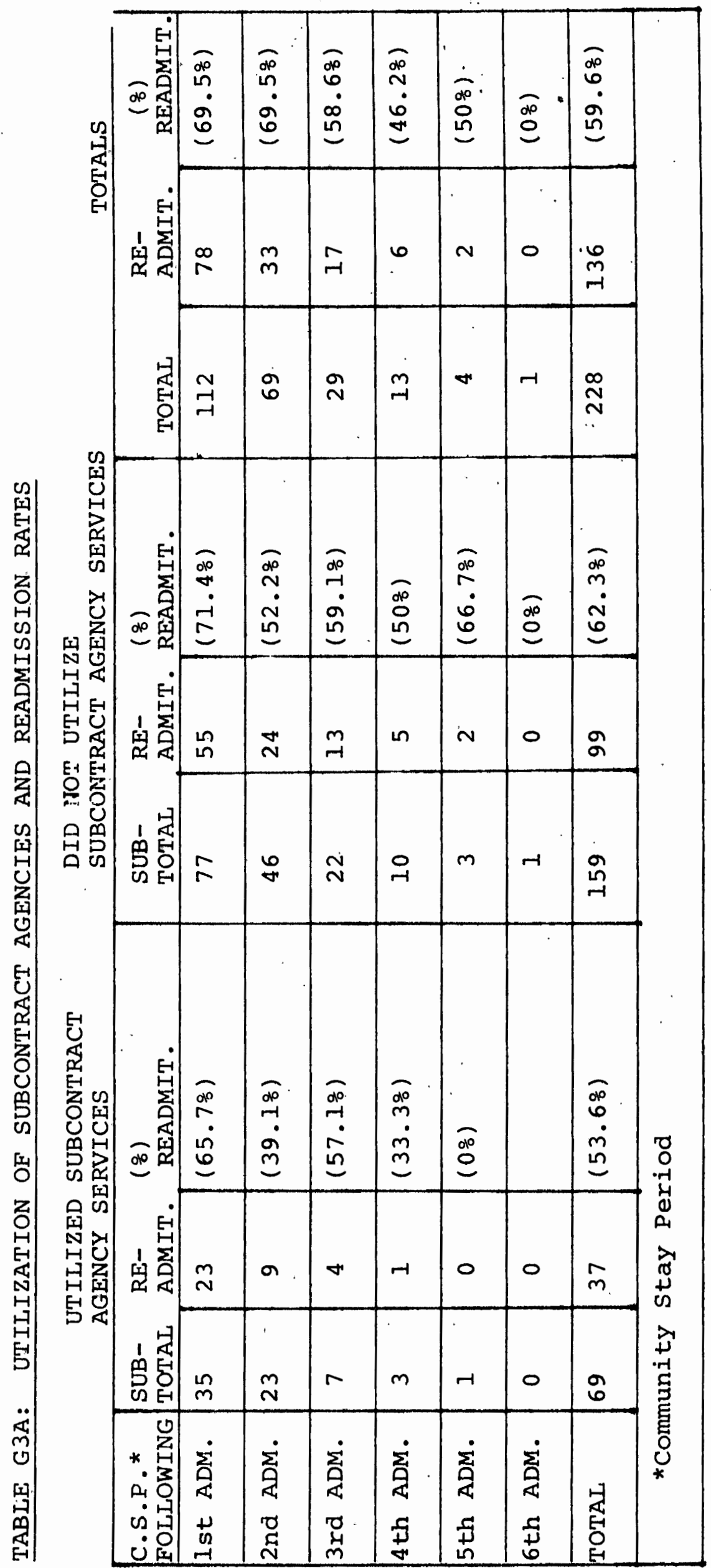




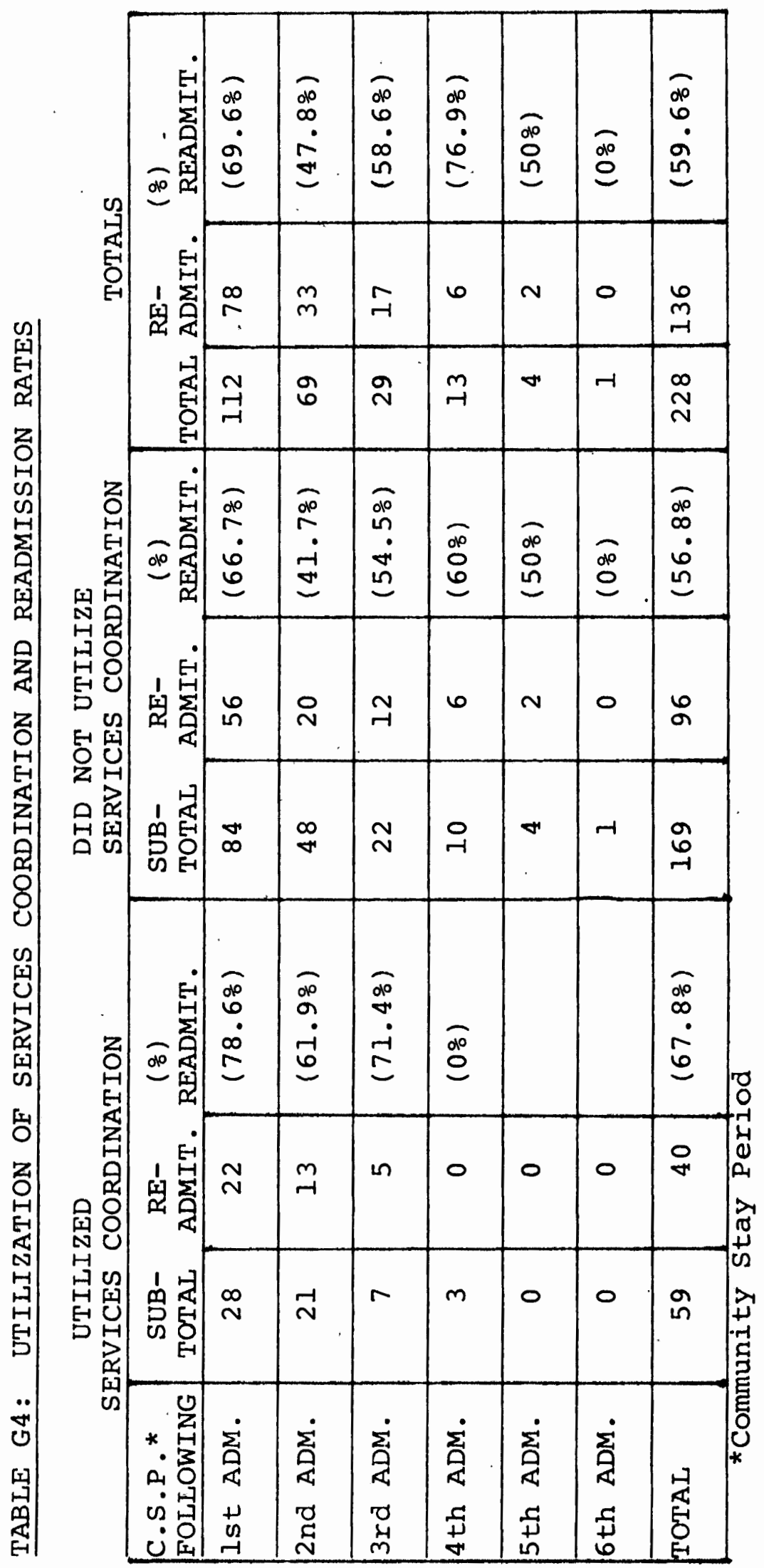


One of the major differences between the subjects who used services coordination and those who did not is that the former group has higher proportions of court committed and psychotic-diagnosed individuals than the latter. In order to determine the effect the concentration of court committed subjects in the former group may have on recidivism, the data shown in Table G5 was compiled. The table shows that comparatively high return rates are associated with services coordination users who had just been released from a court committed hospitalization; while rates achieved by the non-court committed clients were much lower. This finding indicates that most of the difference in recidivism rates between the coordination and non-coordination utilization groups may be primarily due to differences in member characteristics. 
In order to get a clearer picture of how aftercare service utilization and recidivism are related, the population was divided into four utilization categories, and hospital return rates were computed for each category (see Table G6). The four categories are:

1. Subjects who received both services coordination and subcontract services during a community stay period.

2. Subjects who received only subcontract services during a community stay period.

3. Subjects who received only coordination services during a community stay period.

4. Subjects who received no services during a community stay period.

Additionally, to aid in the interpretation of the data, the commitment status and diagnostic characteristics of these four groups were identified. 


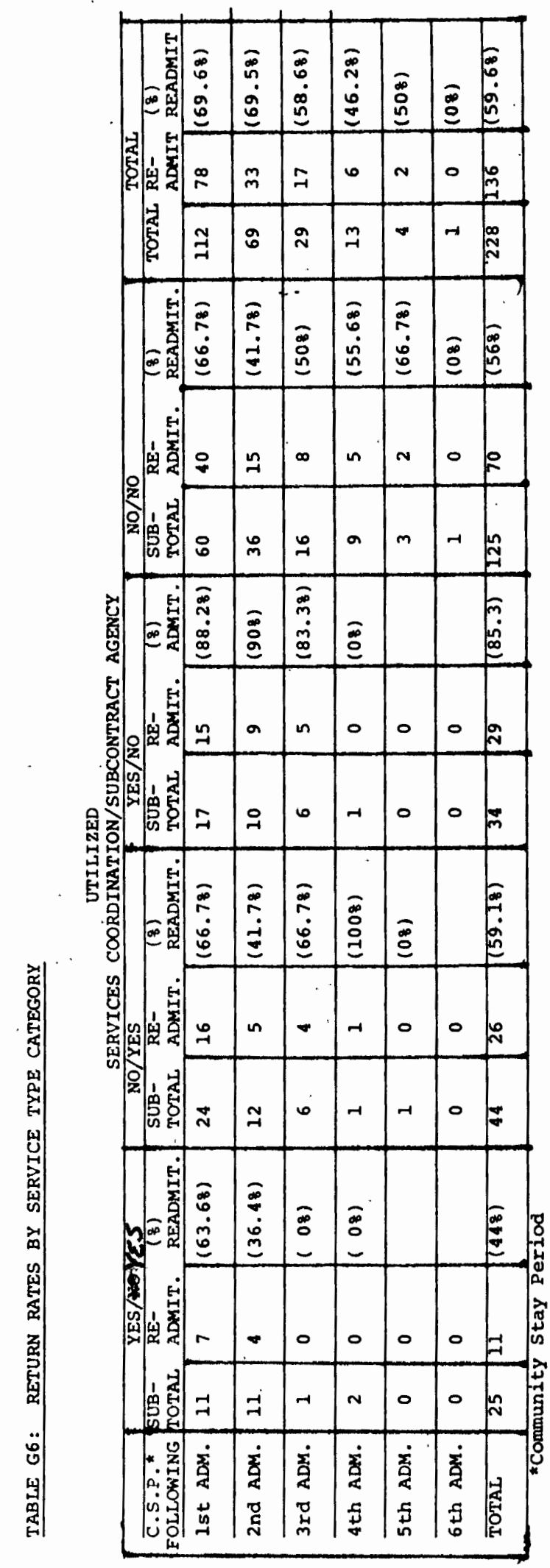




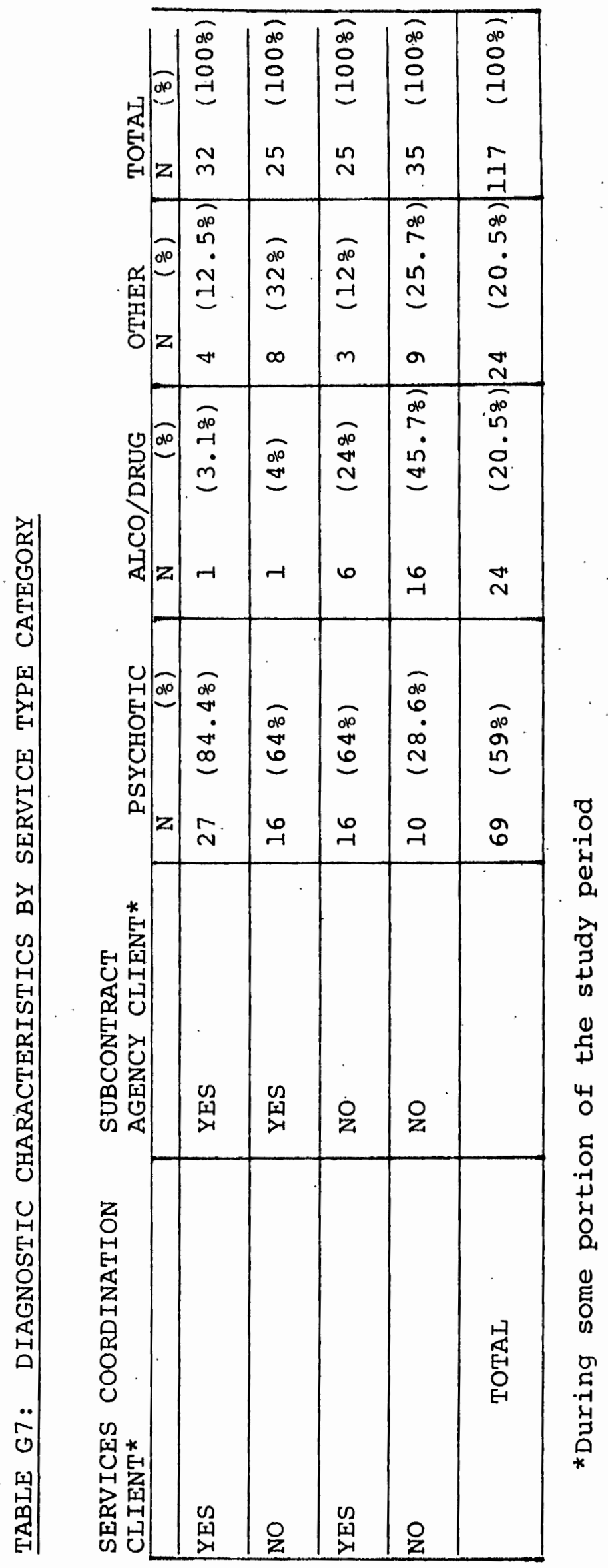




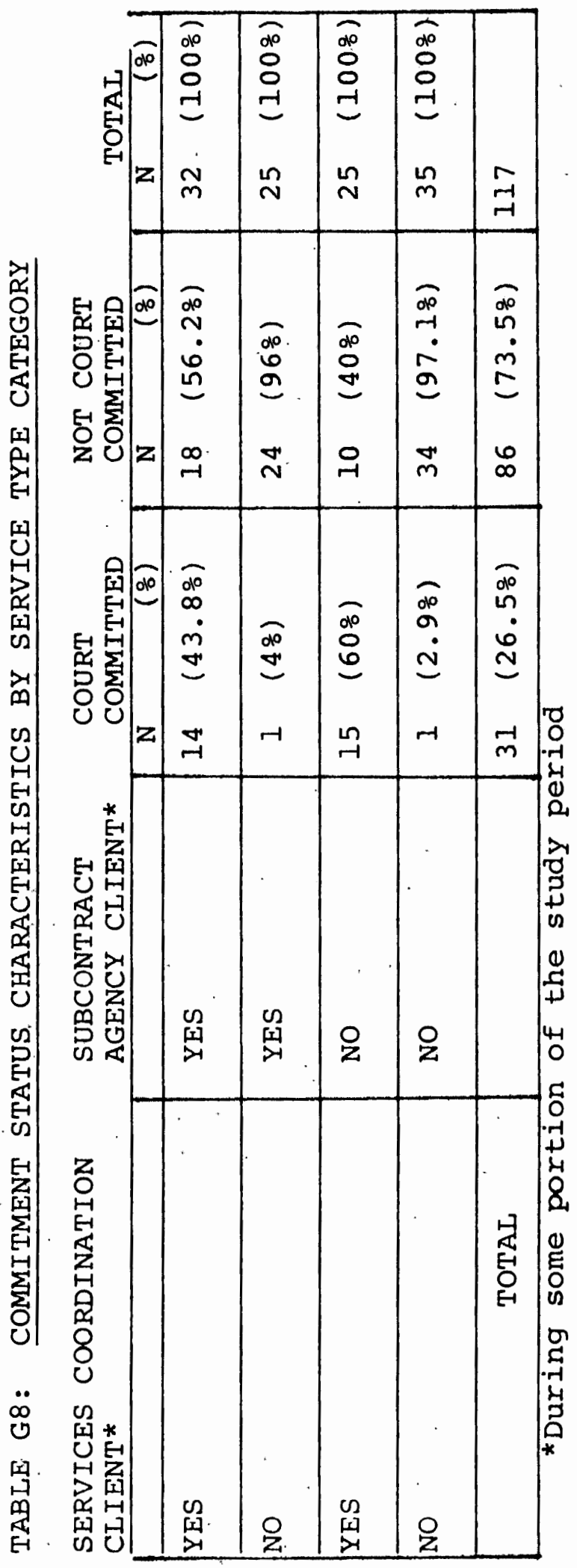


In general, the findings indicate that the lowest return rates are associated with those subjects who use both coordination and subcontract services during a community stay period. The importance of this relationship is further enhanced when one considers that a high proportion (84.4\%) of this group has psychotic disorders and almost half of all members are court committed subjects. The data reported in earlier sections indicates that psychotic subjects tend to be more severely disturbed than other portions of the population. Also, the data already discussed in Table G5 shows that as a whole, court committed coordination clients have generally high hospital return rates. Thus, it seems that with a combination of coordination and subcontract services, high risk portions of the aftercare population are able to maintain comparatively low hospital return rates.

Looking further at Table G8 and considering subgroup characteristics (Tables G6 and G7), the utilization of subcontract services alone is associated with comparatively low hospital return rates while the use of services coordination alone is associated with an extremely high return rate of 85.38 .

The above findings suggest that when services coordination functions as the primary (only) aftercare service (particularly for the more severe portions of the population), hospital return rates remain high. However, 
when this service is provided in tandem with other streatment services, very low return rates can be achieved. 


\section{CHAPTER IV}

\section{SUMMARY OF THE RESEARCH FINDINGS}

The content areas of the following summary generally matches that of the preceding chapter. However, for purposes of clarity and in order to minimize redundancy, the topical flow has been modified and some findings which are felt to be of little interest or tend to restate relationships clarified by other findings have been omitted.

The chronic aftercare population is dominated by Whites and is made up of slightly more males than females. While this group tends to be older than the general population, they are relatively young for an aftercare population. The majority of these individuals are not married and almost half obtained their median $\$ 2,762$ gross annual income through self or family earnings. A little over half of the subjects lived outside of Washington County during some portion of the two year study period. While in the County, the aftercare population tended to be concentrated near the major urban centers of the Tualatin Valley.

On the average, the aftercare subjects have 3.8 lifetime Dammasch State Hospital admissions, with 2.2 of 
those admissions incurred during the two year study period. Between June 31, 1976 and July 1, 1978, an average of 102 days were spent in the state hospital by this group. A clear majority of the hospital admissions were voluntary with approximately one out of five admissions being court commitments.

Almost $60 \%$ of the chronic aftercare population are diagnosed as psychotic. Typically, these individuals tend to be different from the other subjects in ways other than diagnosis. For the most part, this group is younger, yet has more average hospitalizations and longer hospital stays than the other subjects. They are court committed more often, have more unmarried members, and have a slightly higher ethnic composition than the other comparison groups. Out of the remaining 408 of the population that are non-psychotic, half are diagnosed as having alcohol or drug disorders. These individuals tend to have demographic characteristics which are opposite of the psychotic group. These subjects are typically older, have fewer hospital admissions, shorter hospital stays and a higher percentage of married members than the other portions of the population. Those subjects who have diagnoses other than the two already discussed tend to fall between the other two groups on the variables of age, number of hospitalizations, total days in the hospital, and marital status. 
Altogether, 85 (73\%) of the aftercare subjects received client services through the Washington County Mental Health Program or its subcontract agencies or one of Multnomah County's mental health clinics. A total of 83 (7I\%) of these subjects were served by the washington County system:

Once in community (subcontract agency) treatment, the majority of the subjects tended to accumulate in excess of 180 days as a client. Compared to the other agencies, longer treatment stays are associated with Tualatin Valley Mental Health Center and Tualatin Valley Workshop, Inc. clients. These two agencies also tended to provide services to a higher proportion of the more chronically $i l l^{8}$ subjects than the other agencies. There seemed to be little relationship between income and the utilization of subcontract services. At the termination of service, Tualatin Valley Workshop and Metropolitan Family Service were the only agencies who tended (better than 508 of the time) to record in the client case files some indication of the nature of termination. As a whole, the subcontract agencies were very lax in documenting the circumstances of termination.

${ }^{8}$ As measured by hospital admissions, total hospital days, diagnostic category, and commitment status. 
The aftercare services coordination program does appear to be having a positive overall impact on both the utilization of community treatment services and hospital readmission rates. The data tends to show a relationship between the use of coordination services and the utilization (contact and duration). of subcontract treatment services. Additionally, the lowest hospital readmission rates for any of the subgroups compared are associated with those subjects who utilize services coordination in conjunction with subcontract agency services. It is important to note that these low return rates are being achieved on what are considered to be the higher risk portions of the aftercare population. Somewhat increased but still favorable results are associated with the use of subcontract services alone, while the highest return rates are associated with the utilization of coordination services: alone. These findings clearly indicate that the least favorable results are achieved when coordination services are employed in isolation of other treatment services; while the most favorable results are obtained when this service works in association with other treatment services. Finally, as indicated earlier, the aftercare services coordination program is serving less than half of the chronic aftercare population, and a little more than half of those served end up in community treatment services. Since there seems to be little relationship between the 
use of service coordination in isolation of other treatment services and a (comparative) reduction in hospital return rates, it appears that the full positive impact of this program is reaching a minority of the population. 


\section{A SELECTED BIBLIOGRAPHY}

H. Max Drake, et al. An Evaluation of the Deinstitutionalization Process in the U.S. Department of Health, Education, and Welfare, Region $x$. Olympia, Washington: 1978.

Oregon Community Mental Health Programs Data Reporting Procedures Manual, Mental Health Division, Department of Human Resources, Computer Services Unite: Salem, Oregon, 1977.

Washington County Mental Health Program. Washington County Mental Health Plan for the 1979 - $198 \overline{1 \text { Biennium. }}$ Hillsboro, Oregon: 1979. 